Atmos. Chem. Phys., 8, 445-462, 2008

www.atmos-chem-phys.net/8/445/2008/

(C) Author(s) 2008. This work is licensed

under a Creative Commons License.

\title{
Changes in aerosol properties during spring-summer period in the Arctic troposphere
}

\author{
A.-C. Engvall ${ }^{1}$, R. Krejci ${ }^{1}$, J. Ström ${ }^{2,3}$, R. Treffeisen ${ }^{4}$, R. Scheele ${ }^{5}$, O. Hermansen ${ }^{6}$, and J. Paatero \\ ${ }^{1}$ Department of Meteorology, Stockholm University, Stockholm, 10691, Sweden \\ ${ }^{2}$ Department of Applied Environmental Science - Atmospheric Science Unit, Stockholm University, Stockholm, 10691, \\ Sweden \\ ${ }^{3}$ Norwegian Polar Institute, 9296 Troms $\varnothing$, Norway \\ ${ }^{4}$ Alfred-Wegener-Institut für Polar- und Meeresforschung, Telegrafenberg A43, 14473 Potsdam, Germany \\ ${ }^{5}$ Koninklijk Nederlands Meteorologisch Instituut, Postbus201, 3730, AE, De Bilt, The Netherlands \\ ${ }^{6}$ Norsk institutt for luftforskning, Postboks100, 2027 Kjeller, Norway \\ ${ }^{7}$ Finnish Meteorological Institute, P.O.B. 503, 00101 Helsinki, Finland
}

Received: 13 November 2006 - Published in Atmos. Chem. Phys. Discuss.: 25 January 2007

Revised: 26 November 2007 - Accepted: 3 January 2008 - Published: 1 February 2008

\begin{abstract}
The change in aerosol properties during the transition from the more polluted spring to the clean summer in the Arctic troposphere was studied. A six-year data set of observations from Ny-Ålesund on Svalbard, covering the months April through June, serve as the basis for the characterisation of this time period. In addition four-day-back trajectories were used to describe air mass histories. The observed transition in aerosol properties from an accumulationmode dominated distribution to an Aitken-mode dominated distribution is discussed with respect to long-range transport and influences from natural and anthropogenic sources of aerosols and pertinent trace gases. Our study shows that the air-mass transport is an important factor modulating the physical and chemical properties observed. However, the airmass transport cannot alone explain the annually repeated systematic and rather rapid change in aerosol properties, occurring within a limited time window of approximately 10 days. With a simplified phenomenological model, which delivers the nucleation potential for new-particle formation, we suggest that the rapid shift in aerosol microphysical properties between the Arctic spring and summer is mainly driven by the incoming solar radiation in concert with transport of precursor gases and changes in condensational sink.
\end{abstract}

\section{Introduction}

The Arctic's vulnerable eco- and climate system has become a focus of the international scientific community during the last several decades. Recent studies on the Arctic climate showed that, due to its sensitivity to external perturbations,

Correspondence to: A.-C. Engvall

(anki@misu.su.se) the Arctic could be seen as possible early warning of global climate change. Nowadays climate models predict the largest increase of the annual mean temperature for the Arctic (Hassol, 2005).

Unlike many other regions, there are very few local human-derived sources of air pollution in the Arctic in addition to the metallurgical industry in the Russian Arctic. Therefore, the transport of pollution including aerosols and its gaseous precursors from industrialized mid-latitude regions in Europe, Asia, and North America is of great importance. It is suspected that interactions between solar radiation, high surface albedo, the aerosol particles and clouds magnify the radiative impact of atmospheric aerosols in the Arctic region (Quinn et al., 2002). Thus, for a given aerosol distribution, the specific optical impact is most likely increased in this high latitude region.

Experiments conducted in the Arctic over the last 40 years have mainly focused on the Arctic Haze phenomenon, i.e. layers with enhanced concentrations of aerosols and precursor gases in the Arctic troposphere, which is found during late winter and spring. This phenomenon was first noted in the literature of Mitchell (1957). Several years later scientists showed the seasonality to have a very strong annual variation with higher loadings of anthropogenic components during late winter and early spring compared to the summer months and that this perturbation of the Arctic atmosphere was caused by anthropogenic sources at lower latitudes, especially from the Eurasia continent (Rahn, 1981; Barrie, 1986; Heintzenberg, 1989).

Ground-based measurements from the Zeppelin station, Svalbard, and Point Barrow, USA showed that the aerosol loading undergoes a systematic change from spring to summer (Bodhaine et al., 1981; Bodhaine, 1989; Quinn et

Published by Copernicus Publications on behalf of the European Geosciences Union. 
al., 2002; Ström et al., 2003). Results from these studies demonstrated that there is an increase of aged particles, i.e. accumulation-mode particles (particles larger than $100 \mathrm{~nm}$ ) in winter and spring, which are associated with anthropogenic sources and long-range transport. In summer, this mode is significantly smaller in terms of number density. Smaller sized aerosols, so-called Aitken-mode particles, which range between about 20 and $100 \mathrm{~nm}$, dominate the size distribution. At the same time the total particle number density increases.

In this study we will give emphasis on the transition from the more anthropogenic-influenced spring to clean summer conditions. Transport patterns, trace gases, and aerosol microphysics are investigated for the period April through June for the years 2000-2005. It will be shown that the transition from "spring-type" aerosol to "summer-type" aerosol occurs almost at the same time from year to year (give or take a few weeks). We have selected different observational data in order to answer the question if this transition is mainly controlled by changes in the transport of pollutants or if it is an effect of local processes in the Arctic.

\section{Air mass trajectories and long-term measurements from the Zeppelin Station}

\subsection{Air mass trajectories}

The model TRAJKS (Stohl et al., 2001) three-dimensional four-day-back trajectories provided by the Royal Netherlands Meteorological Institute (KNMI) were used to study the link between air mass origin and the aerosol properties. The trajectories were calculated on daily basis at 12:00 UTC in a regular grid centred at $\mathrm{Ny}$-Ålesund $\left(79^{\circ} \mathrm{N}, 11.9^{\circ} \mathrm{E}\right)$ for the period of April through June during the years 20002005. The grid contains, besides the point of Ny-Ålesund, four additional surrounding points in an almost symmetrical grid with sides of about $100 \mathrm{~km}$. Two of the points are located over sea $\left(78.5^{\circ} \mathrm{N}, 14.5^{\circ} \mathrm{E}\right.$ and $79.5^{\circ} \mathrm{N}, 14.5^{\circ} \mathrm{E}$ and the other two are located over land $\left(78.5^{\circ} \mathrm{N}, 9.5^{\circ} \mathrm{E}\right.$ and $79.5^{\circ} \mathrm{N}, 9.5^{\circ} \mathrm{E}$ ). The objective of investigating this grid was to demonstrate how representative the trajectories to $\mathrm{Ny}$ Ålesund are for a larger area of interest and to see possible difference between sea and land areas. Results from this study show that the flow pattern is essentially identical for all five chosen points. Thus for further calculations only the trajectories calculated for $\mathrm{Ny}$-Ålesund $\left(79^{\circ} \mathrm{N}, 11.9^{\circ} \mathrm{E}\right)$ were used.

Garrett et al. (2002) study the aerosol around clouds in the Arctic and found enhanced concentrations of Aitken nucleus above the cloud tops. It is conceivable that there is a source of particles in the FT that are mixed down to the BL. We studied if there are any systematic differences in air transport between the boundary layer (BL) and free troposphere (FT) over the investigated period. The Micro Pulse Lidar (MPL) operated by the National Institute for Polar Research (NPIR) often show cloud tops around $2000 \mathrm{~m}$ altitude (Shiobara et al., 2003). We thus define this altitude as the border between the BL and FT. The so-called level 1 of the MPL data (available through the internet) shows the normalized relative backscatter signals and this data is solely used in the study to get a feeling for typical boundary layer heights based on cloud tops. The $1000 \mathrm{~m}$ and $5000 \mathrm{~m}$ altitudes are then taken to represent airflow in the BL and FT, respectively. Note that the Arctic atmosphere may present several stable layers, and surface inversions are often observed (Tjernström, 2005). However, we are interested in the layering that contains "weather" (clouds and precipitation), which is why we use the altitude range indicated by the MPL.

\subsection{Long-term measurements}

The long-term measurements from the Zeppelin station were used to evaluate temporal variation of the spring-to-summer transition in aerosol properties on a multi-annual basis. The Zeppelin station is located on Mount Zeppelin $474 \mathrm{~m}$ above sea level near the community of Ny-Ålesund, Svalbard. Given the elevated location of the Zeppelin station, the effect of local particle sources such as sea spray and re-suspension of dust from $\mathrm{Ny}$-Ålesund are strongly reduced. However, occasionally the sea salt and dust can contribute significantly to the total mass of the particles. Wind fields over Svalbard are complex, due to the topography and surface characteristics. Compared to ocean level observation, the effects of local wind phenomenon, such as katabatic winds, are reduced at the Zeppelin station. Measurements of chemical and physical properties at the Zeppelin station are included in the Cooperative Programme for Monitoring and Evaluation of the Long-range Transmission of Air Pollutants in Europe (EMEP) and the Global Atmosphere Watch (GAW) program coordinated by the World Meteorological Organization (http://www.wmo.int). Further information about the instrumentation and database are summarized at the homepage http://www.emep.int.

In this study we use aerosol data obtained at the station including number density, size distributions and activity of the radioactive component lead-210 $\left({ }^{210} \mathrm{~Pb}\right)$. In addition we also use sulfur dioxide $\left(\mathrm{SO}_{2}\right)$ and carbon monoxide $(\mathrm{CO})$ measurements to analyse the history and origin of the air masses. Table 1 gives an overview of data availability for the time period of 2000 through 2005 from Zeppelin station used in the present study. In general the data availability is typically better than $90 \%$ complete each year, but some years are not covered by all variables. Year 2002 has low data coverage for aerosol microphysics and less than $50 \%$ of ${ }^{210} \mathrm{~Pb}$ data is available for year 2004 .

The physical properties of the aerosols, such as the total particle number density and the size distribution, are provided by the Department of Applied Environmental Science - Atmospheric science unit (ITM) at Stockholm University. 
Table 1. Available trace gas- and aerosol data used in this study.

\begin{tabular}{|c|c|c|c|c|c|c|}
\hline Trace gas & Unit & $\begin{array}{l}\text { Method used } \\
\text { to measure }\end{array}$ & $\begin{array}{l}\text { Time resolution of } \\
\text { the measured data }\end{array}$ & $\begin{array}{l}\text { Source of } \\
\text { compound }\end{array}$ & $\begin{array}{l}\text { Residence time } \\
\text { in atmosphere }\end{array}$ & $\begin{array}{l}\text { Year and (available } \\
\text { data) }[\%]\end{array}$ \\
\hline $\begin{array}{l}\text { Sulphur dioxide } \\
\mathrm{SO}_{2}\end{array}$ & $\mu \mathrm{gS} \mathrm{m}^{-3}$ & Filter samples & 1 day & $\begin{array}{l}\text { Anthropogenic, } \\
\text { fossil fuels }\end{array}$ & $\sim 4$ days & $\begin{array}{l}2000(100) \\
2001(100) \\
2002(100) \\
2003(100) \\
2004(96) \\
2005(99)\end{array}$ \\
\hline $\begin{array}{l}\text { Carbon monoxide } \\
\mathrm{CO}\end{array}$ & $\mathrm{ppb}(\mathrm{v})$ & Gas chromatography & 1 day & $\begin{array}{l}\text { Biomass burning, } \\
\mathrm{CH}_{4} \text { oxidation, } \\
\text { oxidation natural } \\
\mathrm{HC} \text {, anthropogenic }\end{array}$ & $\sim 1.5$ month & $\begin{array}{l}2002(100) \\
2003(95) \\
2004(98)\end{array}$ \\
\hline Lead $-210{ }^{210} \mathrm{~Pb}$ & $\mu \mathrm{Bq} \mathrm{m}^{-3}$ & $\begin{array}{l}\text { High volume aerosol } \\
\text { sampler }\end{array}$ & Every third day & Earths crust & $\begin{array}{l}\text { From a few days up } \\
\text { to two months }\end{array}$ & $\begin{array}{l}2001(100) \\
2002(100) \\
2003(100) \\
2004(43) \\
2005(100)\end{array}$ \\
\hline $\begin{array}{l}\text { Total particle }\left(\mathrm{N}_{10}\right) \\
\text { number density, } \\
\text { sizes > } 10 \mathrm{~nm}\end{array}$ & $\mathrm{~cm}^{-3}$ & CPC TSI3010 & $1 \mathrm{~h}$ & - & - & $\begin{array}{l}2000(96) \\
2001(91) \\
2002(12) \\
2003(88) \\
2004(99) \\
2005(76)\end{array}$ \\
\hline $\begin{array}{l}\text { Size distribution } \\
\text { size range } \\
20-630 \mathrm{~nm} \text { DMPS }\end{array}$ & $\mathrm{cm}^{-3}$ & $\begin{array}{l}\text { DMA and } \\
\text { CPC TS3760 }\end{array}$ & $1 \mathrm{~h}$ & - & - & $\begin{array}{l}2000(95) \\
2001(93) \\
2002(17) \\
2003(85) \\
2004(97) \\
2005(99)\end{array}$ \\
\hline
\end{tabular}

Hourly data from the Zeppelin station includes total aerosol number density $\left(\mathrm{N}_{10}\right)$ for particles larger than $10 \mathrm{~nm}$ using a Condensation Particle Counter (CPC) model TSI 3010. The size distribution covers the size range from 20 to $630 \mathrm{~nm}$ for year 2000 through 2005 . These are carried out using a custom build Differential Mobility Particle Sizer (DMPS) based on a Hauke type Differential Mobility Analyzer (DMA) (Knutson and Whitby, 1975) coupled to a CPC model TSI 3010. This device uses a closed-loop sheath-air circulation system described by Jokinen and Mäkelä (1997). The aerosol sample flow is $1 \mathrm{~L} \mathrm{~min}^{-1}$, while the sheath airflow is set to $5.5 \mathrm{~L} \mathrm{~min}^{-1}$. This yields a rather broad transfer function, but improves counting statistics during periods of low aerosol loading. When the total number density is $\sim 100 \mathrm{~cm}^{-3}$, the uncertainty arising from counting statistics in the size classes close to mode of the size distribution is less than $5 \%$ (one standard deviation). The mobility distribution measured by the DMA is inverted to a number distribution assuming a Fuchs charge distribution (Wiedensohler, 1988). The final data is given as hourly average. As the particle number concentration ranges over several orders of magnitude the means are calculated as geometric means.
No dedicated cloud-detecting device is available at the Zeppelin station. However, when the station is in cloud, it is typically characterised by low accumulation-mode particle (diameter larger than $100 \mathrm{~nm}$ ) number density as the clouddrops scavenge aerosols from the air. Garrett et al. (2004) observed efficient scavenging of accumulation-mode aerosol, based on aircraft observations in low-level Arctic stratus clouds. As the MPL is placed a few kilometres from the Zeppelin station, the direct link to the clouds at the Zeppelin station is not straightforward. Instead relative humidity (RH) measurements from the Zeppelin station are more pertinent. By collecting meteorological and particle data from the Zeppelin station (available for years 2002 to 2005) we compared RH data with aerosol data, i.e. accumulation-mode numberdensity. Due to periods with sub-zero temperatures, limitations in the sensor, and that aerosol might be affected by clouds above the station via precipitation the RH threshold for cloud affected aerosol data is not exactly $\mathrm{RH}=100 \%$. Calculation of the medians for the accumulation-mode numberdensities gave $60,39,35$ and $30 \mathrm{~cm}^{-3}$ for RH values of 85 , 90,92 , and $95 \%$, respectively. Given the decreasing rate of change in number density as RH increases above $90 \%$ we 


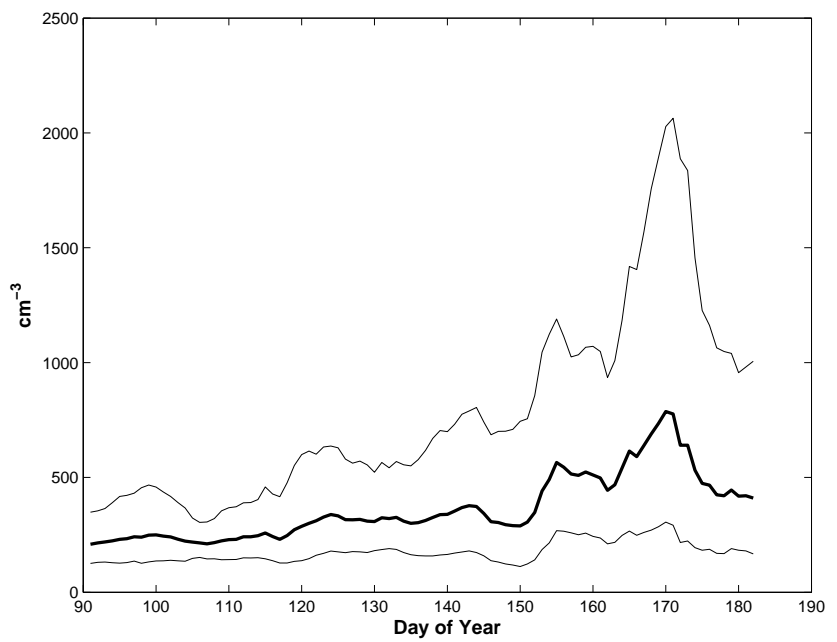

Fig. 1. The total number density, $\mathrm{N}_{10}$, for April through June for the years 2000-2005. Weekly running geometric mean (thick line) and plus minus one standard deviation (thin lines).

subjectively choose $35 \mathrm{~cm}^{-3}$ as a threshold for the cloud affected aerosol. Note that our attempt is to reduce the direct influence of clouds on our analysis not to categorically detect clouds. These low aerosol number-density data, which corresponds to about $22 \%$, were disregarded from further analysis.

The Norwegian Institute for Air Research (NILU) performs long-term measurements of sulfur dioxide $\left(\mathrm{SO}_{2}\right)$ and carbon monoxide (CO). Daily $\mathrm{SO}_{2}$ gas concentrations are measured with $\mathrm{KOH}$-impregnated Whatman 40 filter, which is further analysed with ion chromatography. Gas chromatography with mercuric oxide reduction detection is used for CO measurements (Beine, 1998).

The Finnish Meteorological Institute (FMI) provides data of the activity concentration of lead- $210\left({ }^{210} \mathrm{~Pb}\right)$ on aerosols. ${ }^{210} \mathrm{~Pb}$ concentrations are measured by collection with a hi-volume aerosol particle sampler onto glass fibre filters (Munktell MGA). The sampler is made of stainless steal. The flow rate is about $120 \mathrm{~m}^{3} \mathrm{~h}^{-1}$ and is measured with a pressure difference gauge over a throat. Three samples per week were collected with filter changes on Mondays, Wednesdays and Fridays. One out of the 25 filters is left unexposed and is used as a field blank sample. The measurement of ${ }^{210} \mathrm{~Pb}$ is carried out by alpha counting of the in-grown polonium210 (Mattsson et al., 1996; Paatero et al., 2003). Availability of data for each year (2001-2005) is 100\% except for 2004 when only $43 \%$ of data is available (cf. Table 1 ).

\section{The spring-to-summer aerosol transition}

\subsection{Total number density}

Due to a large range in the number densities, daily geometric means are calculated based on the hourly arithmetically

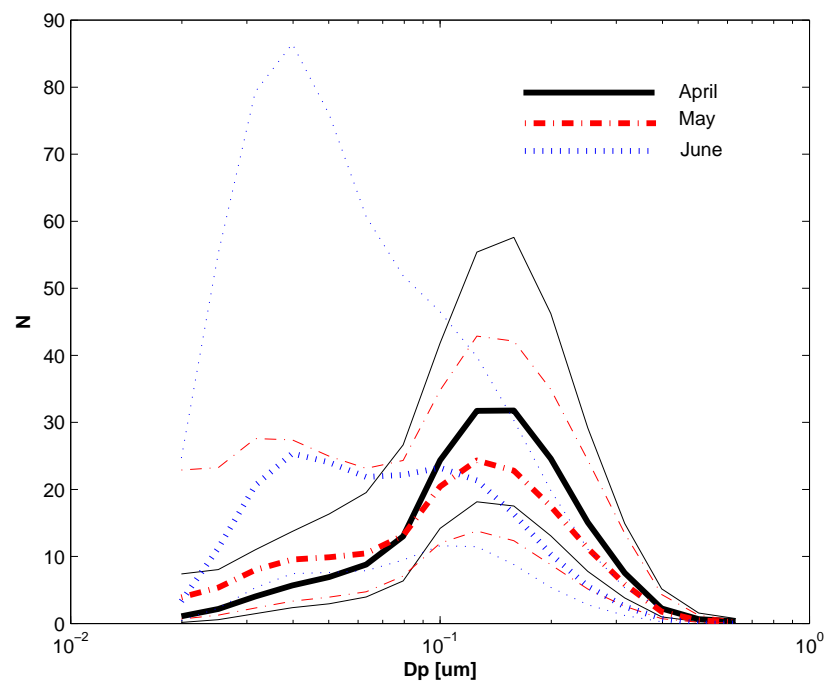

Fig. 2. Monthly geometric mean (bold lines) and standard deviation (thin lines) of the size distributions for the years 2000-2005; Black=April, red dashed=May, and blue dashed dotted=June.

averaged data. The temporal evolution of $\mathrm{N}_{10}$ is presented in Fig. 1. To emphasis major trends in data, a running mean using a weekly window was applied. The months of April and May show a mode around 200 to $300 \mathrm{~cm}^{-3}$ and only few occasions when aerosol number density exceeds $1000 \mathrm{~cm}^{-3}$. June on the other hand shows a distribution that is skewed towards higher aerosol number densities reaching several thousands per cubic centimetre.

\subsection{Particle size distribution}

To illustrate major changes in aerosol size distribution we present a multi-year composite of monthly mean size distributions for each of the three months from April through June, cf. Fig. 2. From these results it is clear that a shift from an accumulation-dominated to an Aitken-dominated distribution occurs over the period April through June. The integral number density for the different distributions does not change dramatically and range from 200 , through 250 , to $300 \mathrm{~cm}^{-3}$ for the consecutive months. When including smaller particles $\left(\mathrm{N}_{10}\right)$ the change in the integral number density from $203 \mathrm{~cm}^{-3}$ in April to $406 \mathrm{~cm}^{-3}$ in June (cf. Table 2) is more pronounced. Hence, a simple approximation can be drawn that around one quarter of the $\mathrm{N}_{10}$ aerosol is smaller than $20 \mathrm{~nm}$ in June.

Based on the size range of the measurements and data availability, we term particles between 22 and $90 \mathrm{~nm}$ Aitkenmode particles and between 90 and $630 \mathrm{~nm}$ accumulationmode particles. The temporal evolutions of these two modes are presented in Fig. 3a as weekly running geometric mean and standard deviation over the six-year period. The accumulation-mode number-density shows a general decrease over the time period. However, the trend is not so 
Table 2. Monthly mean and standard deviation (std) for atmospheric trace gas concentration and aerosol number density.

\begin{tabular}{lllll}
\hline Month & $\begin{array}{l}\mathrm{SO}_{2} \\
\text { mean }(\mathrm{std}) \\
{\left[\mu \mathrm{gS} \mathrm{m}^{-3}\right]}\end{array}$ & $\begin{array}{l}\mathrm{CO} \\
\text { mean }(\mathrm{std}) \\
{[\mathrm{ppbv}]}\end{array}$ & $\begin{array}{l}{ }^{210} \mathrm{~Pb} \\
\text { mean }(\mathrm{std}) \\
{\left[\mu \mathrm{Bq} \mathrm{m}^{-3}\right]}\end{array}$ & $\begin{array}{l}\text { CPC geometric } \\
\text { mean (std range) } \\
{\left[\mathrm{cm}^{-3}\right]}\end{array}$ \\
\hline April & $0.12(0.16)$ & $159(15)$ & $165(134)$ & $203(99-416)$ \\
May & $0.14(0.28)$ & $137(14)$ & $119(72)$ & $287(122-672)$ \\
June & $0.07(0.04)$ & $109(16)$ & $35(27)$ & $406(126-1386)$ \\
Total & $0.11(0.19)$ & $135(25)$ & $113(107)$ & $274(108-698)$ \\
\hline
\end{tabular}

clear within the given data variability. In contrast, the Aitkenmode number-density shows more structure, in the way that an increase from around day 150 is evident in both mean and in variability, indicating increasing importance of the periods with very high aerosol number densities.

Although primary aerosol sources such as sea spray exists in the Arctic, the Aitken-mode particles are primarily a result of secondary particle formation. Through condensation and coagulation the newly formed particles grow into the Aitken mode. These processes will affect the growth of the particles and their residence time in a certain size interval, hence coagulation and condensation is a major source of variability for the Aitken-mode particles (Williams et al., 2002). In Fig. 3a the crossover from an accumulation- to an Aitkendominated size-distribution occurred around day 140 to 150 , which corresponds to the last part of May.

To explore this transition further we generated an alternative figure where we make use of the ratio between the two modes. In Fig. $3 \mathrm{~b}$ a running mean of the ratio $\mathrm{N}_{(22-90)} / \mathrm{N}_{(90-560)}$ from all available data between 2000 2005 is presented. Low numbers below 1 representing that accumulation-mode particle dominates the size distribution and vice versa for values above 1. From Fig. $3 b$ we see that the ratio around day 150 quickly exceeds and remains above 1.5. This indicates that once the change takes place the magnitude of the change in the distribution also increases.

The change in shape of the aerosol size distribution can also be viewed in terms of persistence. In Fig. $4 a-b$ the ratio of days for which the Aitken-mode number-density is larger than the accumulation-mode over a weekly window is presented. We term this the Aerosol Transition Index (ATI). The ATI provides a more distinct measure of when the atmosphere has reached summer conditions i.e. dominance in Aitken-mode particles. From Fig. 4b we notice that the ATI varies greatly between the years. However, the common feature for all years is that ATI, more or less, remains above 0.5 during June. Furthermore, the ATI before day 150 reaches values of up to about 0.9 , but these events only last for a few days. Therefore we chose a threshold value for the ATI to be 0.4 lasting for at least 10 days as a criterion for when summer conditions are reached for the specific year. Based on this criterion, summer conditions are reached around day 145 plus minus one week for each year 2000-2005.
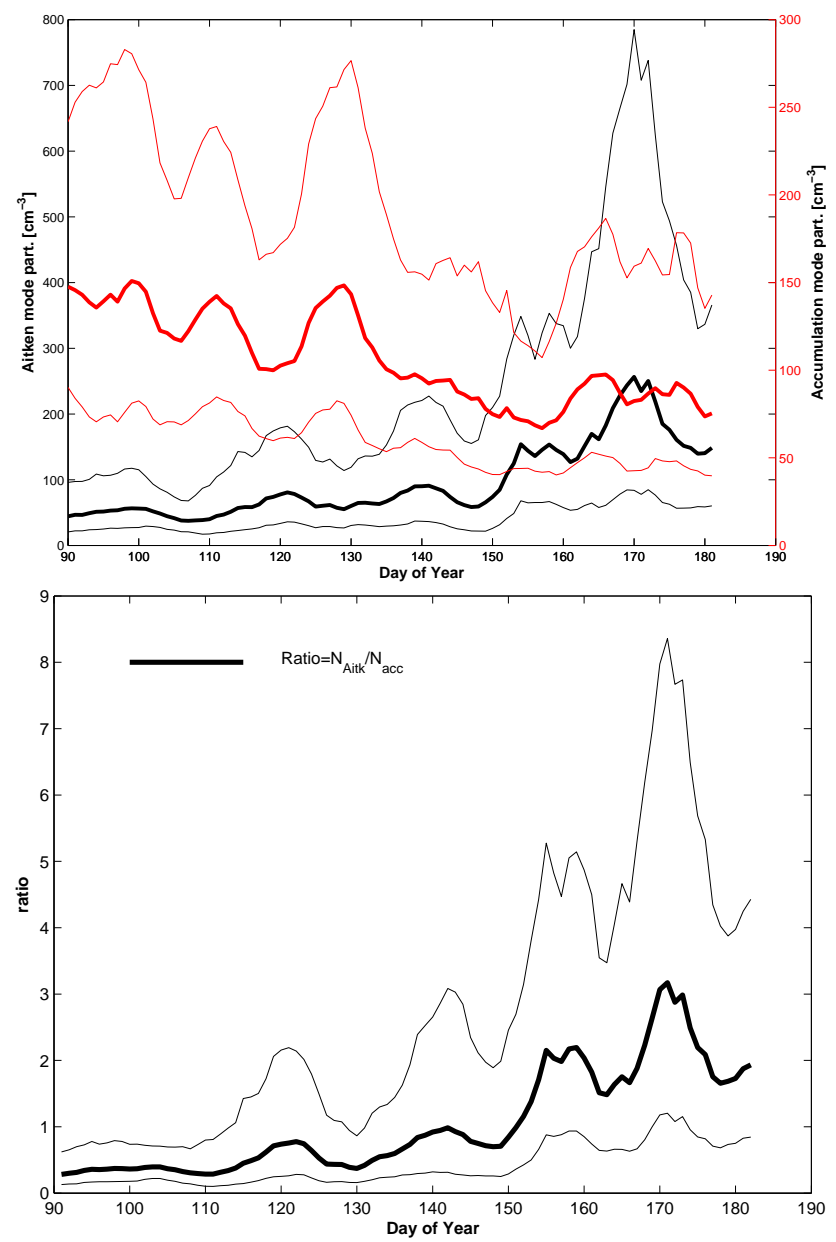

Fig. 3. (a)(Upper panel) Weekly moving average of the Aitkenmode particles $(22-90 \mathrm{~nm})$ (solid line) and the accumulation-mode particles (90-630 nm) (bold dashed line) for the years 2000-2005. (b) (Lower panel) Weekly running mean of the ratio of particle concentration between Aitken mode and accumulation mode, $R_{\text {Ait } / \text { acc }}=\mathrm{N}_{20-90} / \mathrm{N}_{90-630}$ for the years $2000-2005$.

The criterion ATI $=0.4$ is on one hand subjectively chosen. Setting a value ATI between 0.3 and 0.5 does not, however, really change the threshold for when "summer conditions" 

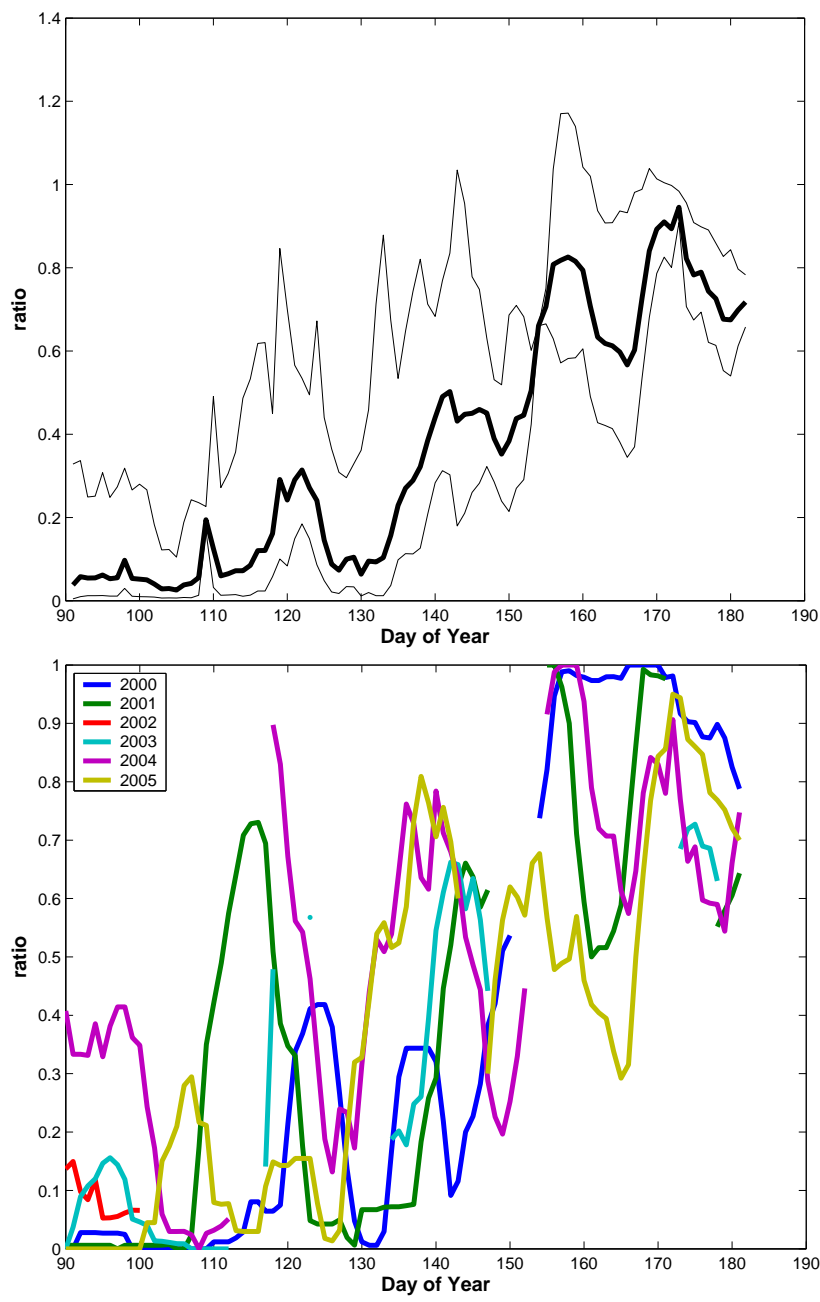

Fig. 4. (a) (Upper panel) Weekly running mean and std of the Aerosol Transition Index (ATI), defined by the ratio between the frequencies of ratios $R_{\text {Ait/acc }}>1$ divided by the frequency of ratios $R_{\text {Ait } / \text { acc }}<1$ for a period of one week, for the years 2000 through 2005. (b) (Lower panel) same as (a) but weekly running mean for each year of the Aerosol Transition Index (ATI), for each year 2000-2005.

are true. The objective to introduce the ATI is to use it as a tool for future analyses of the variables from the Zeppelin station and give a measure for when summer conditions hold true regarding the aerosols in the region.

\section{Coupling between aerosol properties, anthropogenic tracers, air-mass transport, and aerosol microphysics}

\subsection{Long-range transport}

The seasonal variation of the transport patterns to $\mathrm{Ny}$ Ålesund $\left(79^{\circ} \mathrm{N}, 11.9^{\circ} \mathrm{E}\right)$ in the form of air mass trajectory is summarised in climatology for the period 1991-2001 by
(Eneroth et al., 2003). Five-day back-trajectories were calculated two times a day (00:00 and 12:00 UTC) and were divided into eight major transport patterns (clusters). Their study showed the variability of the atmospheric circulation on a synoptic scale, month-to-month and year-to-year. They derived clear seasonal differences due to the difference in the strength of pressure gradients between the seasons. Longest trajectories (equal to a fast transport from lower latitudes of the Atlantic and Eurasia continent) are found during the winter season and shortest (equal to a slow transport) during summer season. Spring, defined as mid April to May, is associated with stable weather conditions and low cyclonic activity, which favour persistent airflow from the Arctic, and slow transport from northern part of Russia, Scandinavia and the Atlantic. The fast transport associated with storm tracks from the Atlantic is shown to be infrequent during this period. The summer period (June, July and August), on the other hand, is associated with weak pressure gradients. During this period the transport from anthropogenic sources is not as efficient as during winter and spring.

In this section we will extend their study and emphasis on airflow patterns over a limited period of the year and furthermore link air-mass transport, anthropogenic tracers and aerosol properties. Our aim is to produce an overview of the temporal evolution of the air-mass transport to $\mathrm{Ny}$-Ålesund.

\subsubsection{Vectorized trajectories}

For this study we have calculated 546 four-day-back trajectories for two altitude levels, 1000 and $5000 \mathrm{~m}$, from April through June for the years 2000 through 2005 (see details Sect. 2). A variable called "trajectory vector" was derived to relate the large numbers of trajectories to the tracer data. For each trajectory the radius of gyration was calculated. This summarizes all the intermediate time steps of the trajectory into one vector, with a direction and a magnitude. The direction yields the main flow direction of the trajectory and the magnitude yields and indication of the speed with which the air travelled. From this trajectory vector we are further able to calculate the north-south (N-S) and east-west (E-W) contribution of the air-mass transport to Ny-Ålesund. These open up the possibility to reduce trajectory information into single parameter and produce time series, which allow investigation of the air-mass transport temporal evolution. Furthermore, we use these time series of the trajectory vectors to evaluate the hypothesis that the air-mass transport controls the transition of the aerosol properties between spring and summer.

The coordinates are relative to Ny-Ålesund $79^{\circ} \mathrm{N}, 11.9^{\circ} \mathrm{E}$ i.e. projection of the trajectory vector to the $\mathrm{x}$-axis give us the contribution in the E-W direction relative to longitude $11.9^{\circ}$ and projection to the $y$-axis the contribution in the $\mathrm{N}-\mathrm{S}$ direction of latitude $79^{\circ} \mathrm{N}$. A positive (negative) value of the $\mathrm{x}$ - and $\mathrm{y}$-axis represents air from the east (west) and north (south). Note that we, at an early stage, compared the 

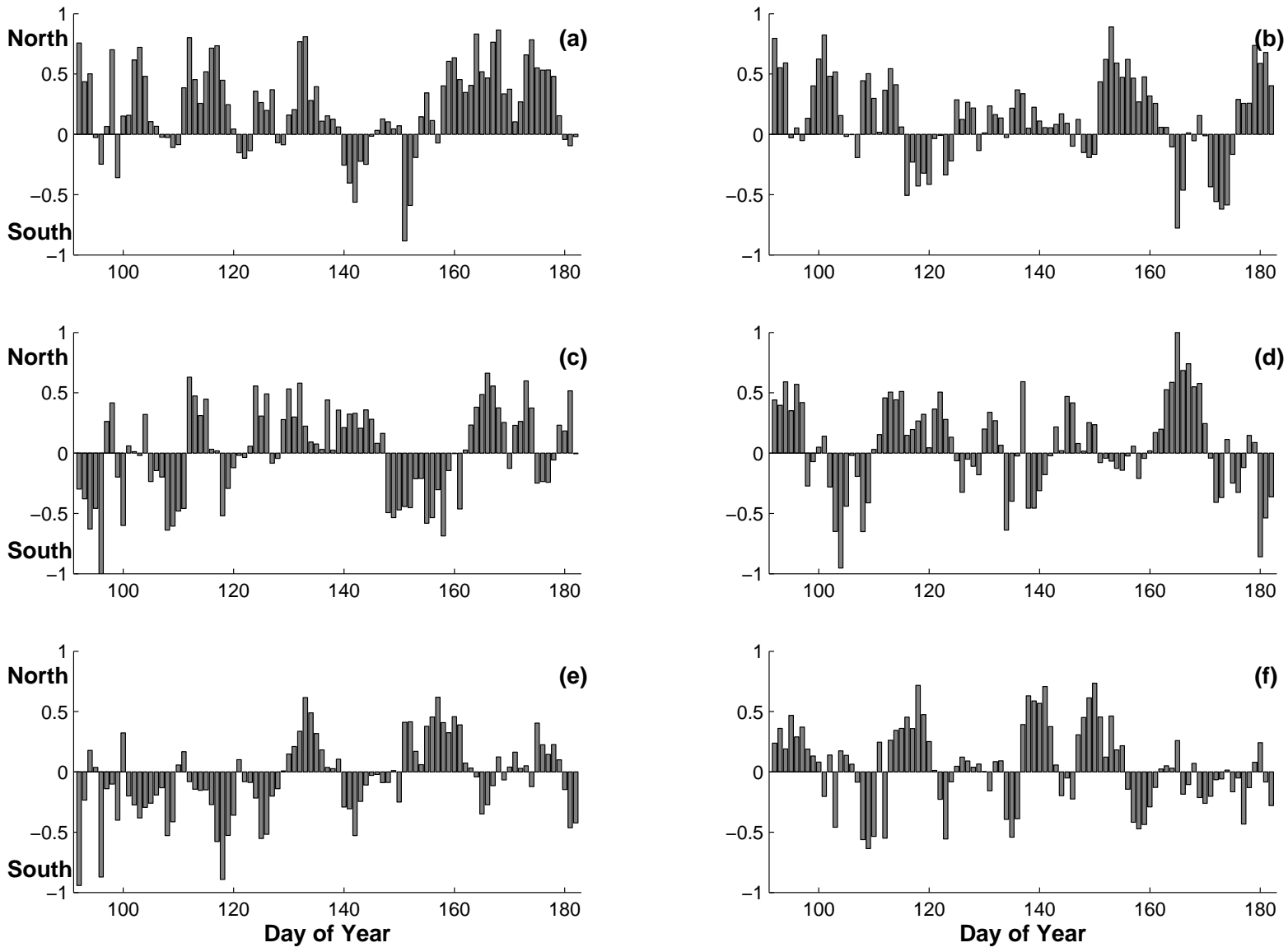

Fig. 5. The vectorized trajectories arriving to altitude-level $1000 \mathrm{~m}$ plotted with time (day of the year) for each year 2000-2005 (a-f). Y-axis shows the normalized North-South $(\mathrm{N}-\mathrm{S})$ contribution for the air-mass transport.

four-day-back trajectories with ten-day-back trajectories and they did not show significant difference with respect to our approach to the air mass origin used in the study. Therefore we continue to use four-day trajectories throughout the study.

\subsubsection{Transport patterns}

Combining the N-S and E-W component for each day gives us the horizontal information of the trajectory with respect to the direction and magnitude. Figure 5a-f presents the calculated N-S contribution for each day that the trajectory arrived to level $1000 \mathrm{~m}$ (BL) for the time period from 2000 through 2005 (similar research has been performed for level $5000 \mathrm{~m}$ (FT), as it does not give any additional information it is not shown here). From Figs. 5a-f there are no apparent trends that could link to and explain the transition in aerosol properties, i.e. corresponding rapid and repeating change from a more polluted origin in the spring to a more clean origin in the summer.

The short analysis above has essentially provided information about the horizontal transport. To investigate the vertical dimension we also calculated the time the trajectory has spent in the boundary layer during the last four days of its transport to Ny-Ålesund. The different years are then averaged for each day of the investigated time period and are expressed as fraction time to the total time-length of the trajectory. In this context we define the BL to be altitudes below $2000 \mathrm{~m}$. This altitude often represents the top of the lowlevel clouds as seen by MPL at Ny-Ålesund. The exceptions are cases when the air arrives within a sector that belongs to the Arctic basin i.e. representing the area within the two tangents with origins in the coordinates of Ny-Ålesund and tangents the north coast of Greenland and the northern coast of Siberia. Within this sector the BL height is defined as $1000 \mathrm{~m}$. This difference in definition in BL takes into account the stable stratification over the pack ice, especially during the summer months (Nilsson, 1996).

The calculated fraction ranges from 0 to 1 , where 1 represents a trajectory that spends all its time in the BL. The temporal evolution of this fraction is depicted in Fig. 6. The upper and lower panels represent trajectories arriving to $\mathrm{Ny}$ Ålesund at the altitude level 1000 and $5000 \mathrm{~m}$, respective. Not surprisingly trajectories arriving at a lower altitude spend 

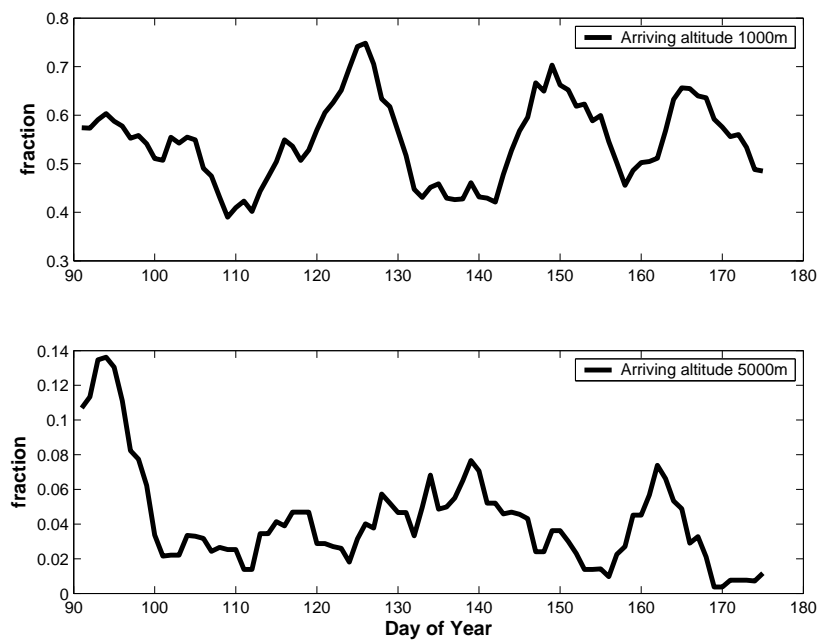

Fig. 6. The relative fraction mean time, each day trajectory has spent in the boundary layer (BL) defined as altitudes below $2000 \mathrm{~m}$ (1000 $\mathrm{m}$ for the Arctic region), for the years 2000-2005. The upper panel represents trajectory that arrive to the altitude level of $1000 \mathrm{~m}$ and lower panel trajectories that arrive to the altitude of $5000 \mathrm{~m}$.

more time in the BL. Comparing the start and end of the period we notice a decreasing trend in ratio of high-level trajectories spending time in the BL (lower panel). But these trends are not very strong and do not show the radical change between day 140 and 150 that the aerosol properties do.

\subsection{Anthropogenic tracers}

In previous sections we have shown that transport alone cannot explain the transition in aerosol properties observed on annual basis. Here we will explore the possibility that the combination of various transport patterns and seasonal changes in the anthropogenic sources strength can shed a light on observed aerosol microphysics. The tracers used in this analysis serve as proxy for air-mass characteristics. They are not necessarily intended to address long-range transport of small aerosol particles, but rather to indicate changes in the composition of the air with respect to aerosol precursors and pre-existing particles. To follow this hypothesis we use data of anthropogenic tracers $\mathrm{SO}_{2}, \mathrm{CO}$ and ${ }^{210} \mathrm{~Pb}$ observed at the Zeppelin station and focused on their temporal variation.

$\mathrm{SO}_{2}$ is one of the major anthropogenic trace gases and highly relevant to aerosol properties. Additional to the anthropogenic source it also has a natural biogenic source contributing to $\mathrm{SO}_{2}$ in the atmosphere through oxidation of dimethyl sulphide (DMS) (Li and Barrie, 1993; Li et al., 1993; Ferek et al., 1995). We also explored measurements of $\mathrm{CO}$ and ${ }^{210} \mathrm{~Pb}$ because in the Arctic the occurrence of these can be attributed exclusively to sources outside of the Arctic. We will use them as major tracers for anthropogenic source regions (Paatero et al., 2003). Figure $7 \mathrm{a}$ and $\mathrm{b}$ shows the weekly running mean of $\mathrm{SO}_{2}$ and
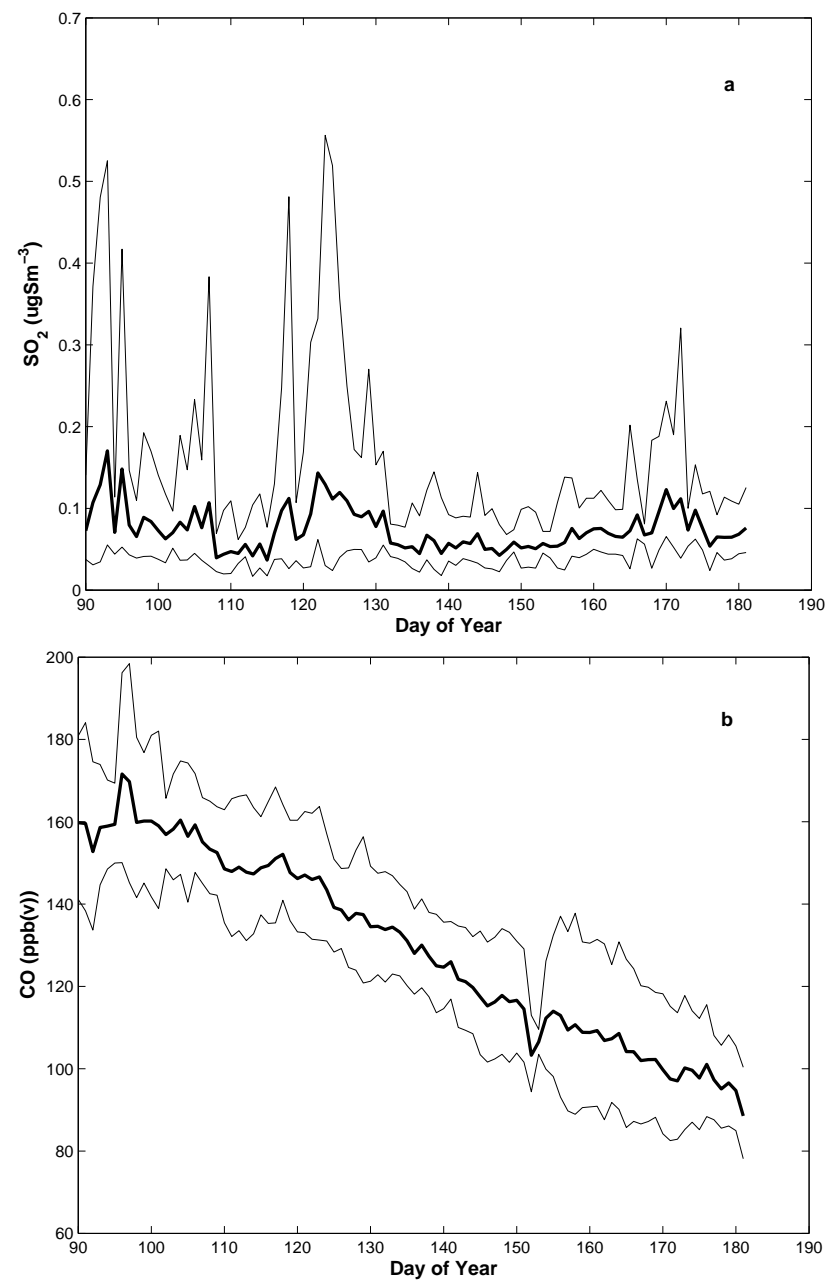

Fig. 7. Weekly running mean (thick lines) and plus minus one standard deviation (thin lines) of the trace gases $\mathrm{SO}_{2}$ (a) and $\mathrm{CO}$ (b) measured at the Zeppelin station for the years 2000-2005 and 20022004, respectively.

CO. $\mathrm{SO}_{2}$ shows a large intra-annual variability in data for the period with episodes of high values in April and May and rather low concentration in June. The concentrations range between a minimum value of $0.01 \mu \mathrm{gS} \mathrm{m}^{-3}$ (effective detection limit) to a $2.13 \mu \mathrm{gS} \mathrm{m}^{-3}$ and a median of $0.07 \mu \mathrm{gS} \mathrm{m}^{-3}$. The monthly mean and standard deviation of $\mathrm{SO}_{2}$ show the maximum to occur in May with $0.14(0.28) \mu \mathrm{gS} \mathrm{m}^{-3}$ and a trend that decreases towards June with corresponding values of 0.07(0.04) $\mu \mathrm{gS} \mathrm{m}^{-3}$ (cf. Table 2).

The high variability of $\mathrm{SO}_{2}$ in April and May reflects the frequent fast transport from anthropogenic sources that take place during springtime, whereas in June it is more associated with lower background concentrations perturbed by occasional higher values but not as high as April and May. The source of DMS is anticipated to be at its largest in late summer (August) according to study by (Ferek et al., 1995). They reported Arctic DMS concentration up to $300 \mathrm{ppt}$, 
while background concentrations stayed at a few tens of ppt. If the observed DMS concentrations were converted to sulfur (S) at $100 \%$ efficiency it would give a background level of approximately $0.04 \mu \mathrm{gS} \mathrm{m}^{-3}$ and the highest peak would correspond to about $0.4 \mu \mathrm{gS} \mathrm{m}^{-3}$. This maximum value is still well below the peaks observed in the springtime at the Zeppelin station. There is nothing in the $\mathrm{SO}_{2}$ trend that would suggest that an increased biogenic source would explain the observed sudden transition in aerosol properties. For year 2005, $\mathrm{SO}_{2}$ shows a mean concentration of $0.13 \mu \mathrm{gS} \mathrm{m}^{-3}$, which differs from other years where the mean concentration is much lower $\left(0.07 \mu \mathrm{gS} \mathrm{m}^{-3}\right)$. Over all sample years we note that after day $140 \mathrm{SO}_{2}$ infrequently exceeds $0.07 \mu \mathrm{gS} \mathrm{m}^{-3}$. The only characteristic that could relate to the aerosol transition is the fewer occurrences of higher $\mathrm{SO}_{2}$ levels after day 140. However, this trend would tend to decrease the potential for new particle formation.

$\mathrm{CO}$ in Fig. 7b follows a clear decreasing trend during the period. Carbon monoxide has a longer residence time (around 90 days) in the atmosphere compared to $\mathrm{SO}_{2}$ (57 days), which explains much of different features between Fig. 7a and b. The total mean and standard deviation of $\mathrm{CO}$ concentration is $135(25)$ ppbv, which is about 9\% lower compared to yearly base mean presented by Beine (1999). Aside from some small deviation around day 155, the trend in $\mathrm{CO}$ shows a rather smooth decrease over time. Variability is also relatively constant over the period. As $\mathrm{OH}$ acts as a major sink for $\mathrm{CO}$, the annual cycle of hydroxyl radical $\left({ }^{\bullet} \mathrm{OH}\right)$ is of major importance for the seasonal evolution of $\mathrm{CO}$. $\mathrm{OH}$ is produced by photochemical reactions and therefore depends on incoming solar radiation. Observations show that $\mathrm{CO}$ accumulates in the Arctic troposphere during wintertime due to transport processes and the fact that sink processes by $\mathrm{OH}$ are not available. During spring when the sun rises the sink processes for $\mathrm{CO}$ become active and the $\mathrm{CO}$ concentrations start to decrease, with the minimum reached in summer (Dianovklokov and Yurganov, 1989). The steady state decrease of $\mathrm{CO}$ mixing ratios, only slightly perturbed by local maximum, correlated with episodes of higher $\mathrm{SO}_{2}$, also indicates that dilution and mixing with clean air masses and photochemical sink of $\mathrm{CO}$ dominates over the source in the form of long-range transport during April-June period.

Lead-210 $\left({ }^{210} \mathrm{~Pb}\right)$ originates almost exclusively from continents and as such it is a tracer of air masses having rather recent contact with landmasses. With its long lifetime (halflife 22 years) the atmospheric lifetime is mainly governed by the lifetime of the aerosols (Paatero et al., 2003). Most of the atmospheric ${ }^{210} \mathrm{~Pb}$ is attached to accumulation-mode aerosols. Based on the activity ratio of ${ }^{210} \mathrm{~Pb}$ and its progeny; mean aerosol residence times can be estimated. In the present study we only investigate the temporal variation of ${ }^{210} \mathrm{~Pb}$ data itself. The annual variation of the activity concentration of ${ }^{210} \mathrm{~Pb}$ at the Zeppelin station was between 11 and $620 \mu \mathrm{Bq} \mathrm{m}^{-3}$ for the year 2001 (Paatero et al., 2003). The maximum was observed in March-April and the minimum in
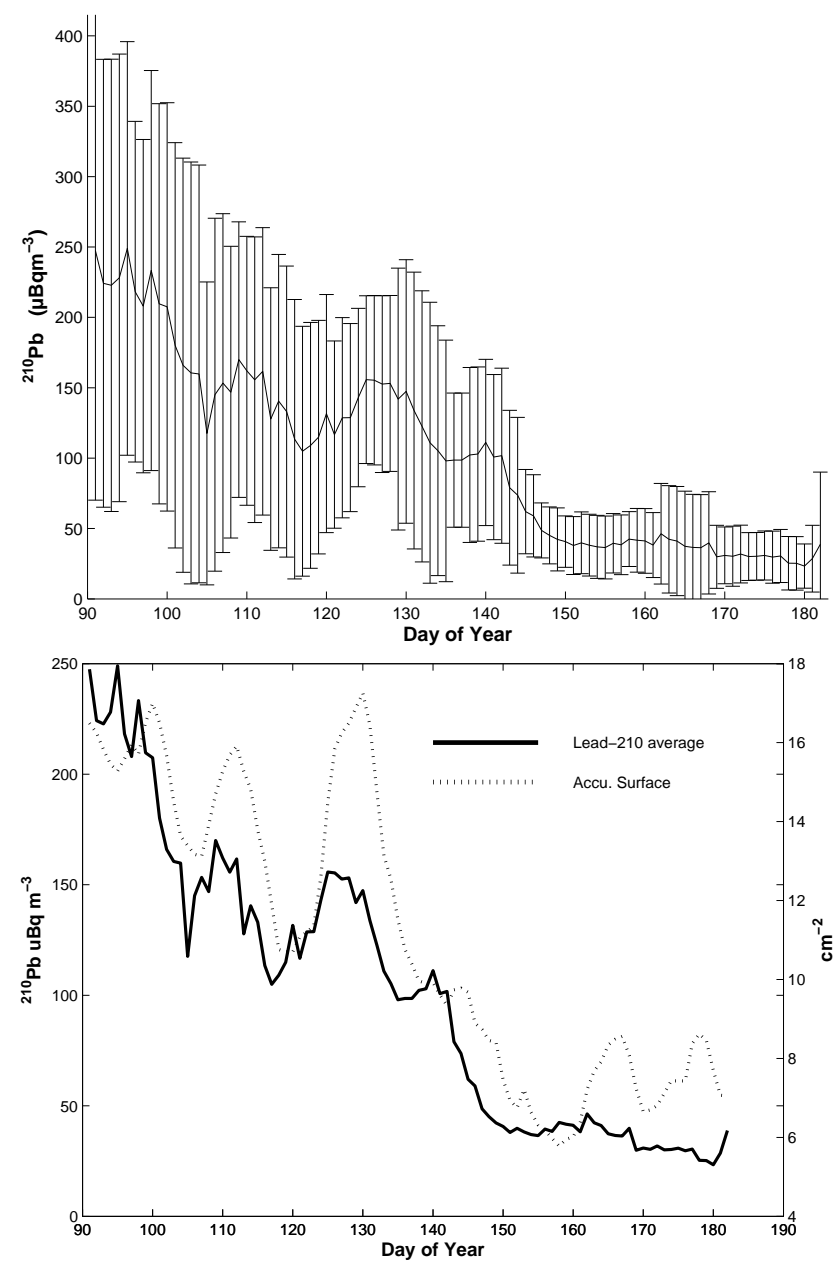

Fig. 8. (a) (Upper panel) the activity concentration of lead-210 on aerosols measured at the Zeppelin station 2001-2005. Weekly running average and error bars representing one standard deviation. (b) (Lower panel) the averaged lead-210 concentration plotted together with the average accumulation-mode $(90-630 \mathrm{~nm})$ particles surface.

summer. In the present study the ${ }^{210} \mathrm{~Pb}$ activity concentration vary between 0 and $552 \mu \mathrm{Bq} \mathrm{m}^{-3}$. The data presented in Fig. 8a agree well with the single-year study by Paatero et al. (2003); maximum values in April with a monthly mean and standard deviation of 165 and $134 \mu \mathrm{Bqm}^{-3}$, respectively, and a much lower mean in June of $35(27) \mu \mathrm{Bq} \mathrm{m}^{-3}$.

Lead-210 is one of the tracers investigated in this study that shows a notable change in both the rate at which it decreases and its variability. In particular the decrease in variability is very evident. It is worthy to note again that ${ }^{210} \mathrm{~Pb}$ is associated with accumulation-mode particles and thus could be a proxy of relative increase or decrease of the aerosol surface area, which are also dominated by accumulation-mode aerosol (Fig. 8b). 

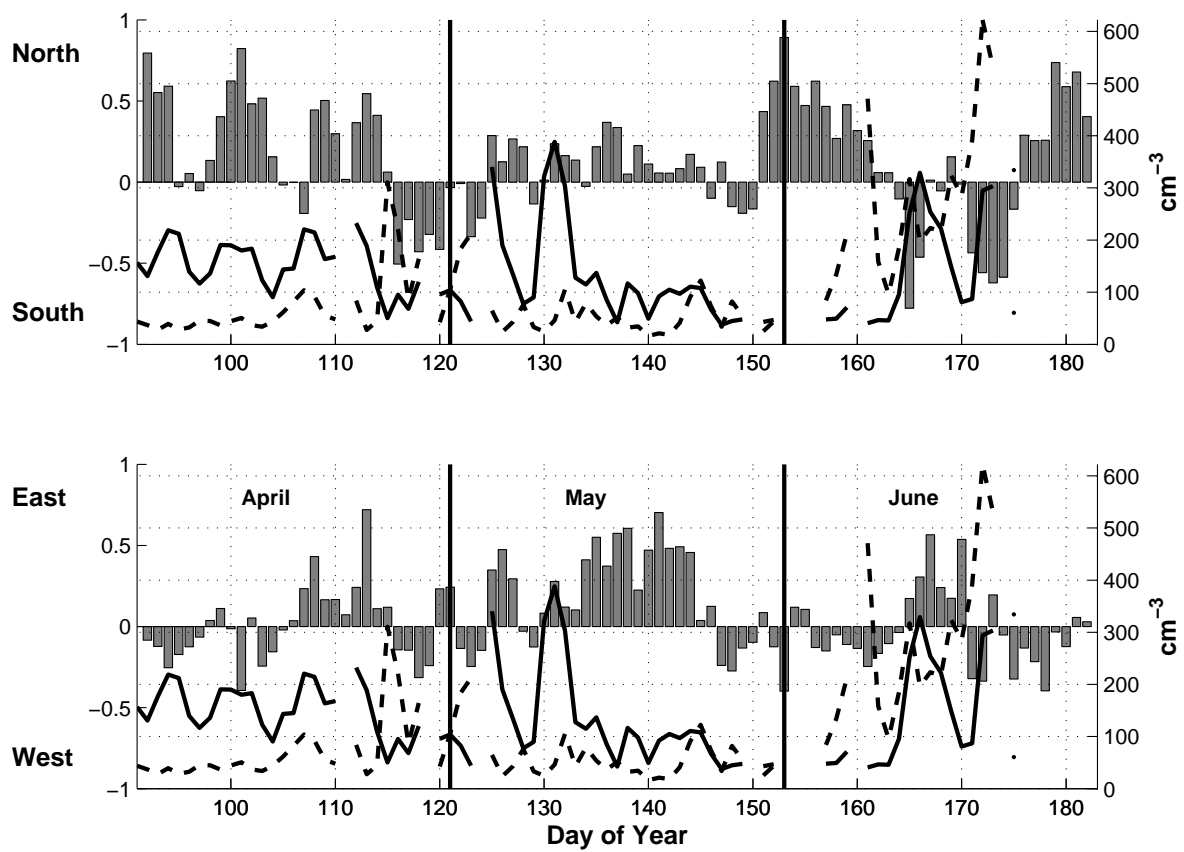

Fig. 9a. Vectorized trajectory for each day of 2001. Upper figure shows the N-S vs. the particle densities of the Aitken-mode particles (dashed line) and accumulation-mode particles (solid line). Lower figure shows the corresponding E-W contribution for each day trajectory.

4.3 Coupling between the aerosols, anthropogenic tracers and air-mass transport

In Sect. 3.2 we have demonstrated that the Aitken-mode particles show an increasing trend in number density from April to June and the accumulation-mode particles show a slow decreasing trend. With the obtained vectorized trajectories (cf. Sect. 4.1) we will in this section couple the horizontal air-mass transport to the loading of the aerosols and the anthropogenic tracers loading for each day. Investigations have been performed for all years but we select one year, 2001, to illustrate our findings, as this year has the most complete data set available (cf. Table 1).

Figure 9a (upper panel) shows the N-S component together with the daily average of the accumulation-mode (solid line) and Aitken-mode particles (dashed line) and the lower panel the corresponding E-W component. Combining the information of these two graphs one can follow the aerosol loading and the main direction of the air-mass transport. For example the accumulation-mode particles reach values between 300 and $400 \mathrm{~cm}^{-3}$ during days 125 and 132. The vectorized trajectories for these days show a NE contribution. A further look at the specific trajectories for these days shows that the air mass originate from the northerly part of Russia, Siberia, and they are most likely affected by anthropogenic sources, e.g. metal smelter at Norilsk (Virkkula et al., 1995). This is also supported by the $\mathrm{SO}_{2}$ and ${ }^{210} \mathrm{~Pb}$ data that show peaks of enhanced concentrations cf. Fig. 9b-c.
${ }^{210} \mathrm{~Pb}$ data has a lower data rate (one sample every third day) compared to particle data and $\mathrm{SO}_{2}$ data (reason for the non-continues line in Fig. 9c). This makes it hard to make accuracy comparisons of ${ }^{210} \mathrm{~Pb}$ and for individual values of accumulation-mode densities and $\mathrm{SO}_{2}$. As it is shown in Fig. $8 \mathrm{a}$, the average concentration of ${ }^{210} \mathrm{~Pb}$ decreased during the period from April through June with an order of more than 5. In an earlier study the effect of the North American continent on the airborne ${ }^{210} \mathrm{~Pb}$ in northern Finland was observed (Paatero and Hatakka, 2000). As mentioned before, the residence time for ${ }^{210} \mathrm{~Pb}$ can vary from a few days up to a month depending on how effective the scavenging of the particles from the atmosphere are. Less efficient scavenging of the particles might be depicted in the maximum value $\sim 450 \mu \mathrm{Bq} \mathrm{m}^{-3}$ observed in April, compared to the median value of $133 \mu \mathrm{Bq} \mathrm{m}^{-3}$ for the entire period. Enhanced values later during the period, days 130-135, are concurrent with enhanced values of the density of accumulation-mode particles (Fig. 11a) and $\mathrm{SO}_{2}$ (Fig. 11b) and are coupled to northeasterly flow from northern part of Eurasia.

The data presented show that the air-mass origin and transport are important factors controlling the aerosol microphysical properties, but against the expectations air-mass transport alone cannot explain the spring-to-summer transition in aerosol properties at all. Moreover, it is very likely that other processes are of the same or higher importance and this alternative scenario will be discussed in following section. The variable showing most of a spring-to-summer transition other than the aerosol is ${ }^{210} \mathrm{~Pb}$. On the other hand the 

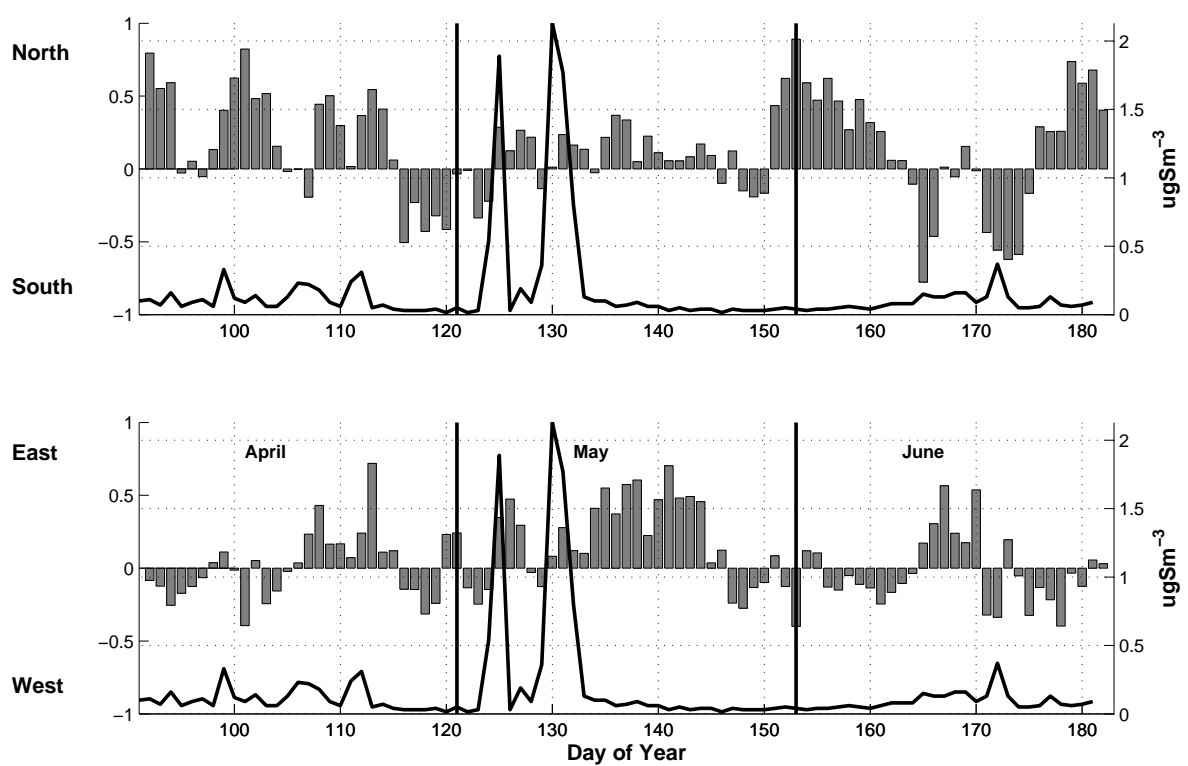

Fig. 9b. Each day vectorized trajectory for 2001. Upper figure shows the $\mathrm{N}-\mathrm{S}$ together with $\mathrm{SO}_{2}$ concentration (line). Lower figure shows the corresponding E-W contribution for each day trajectory.
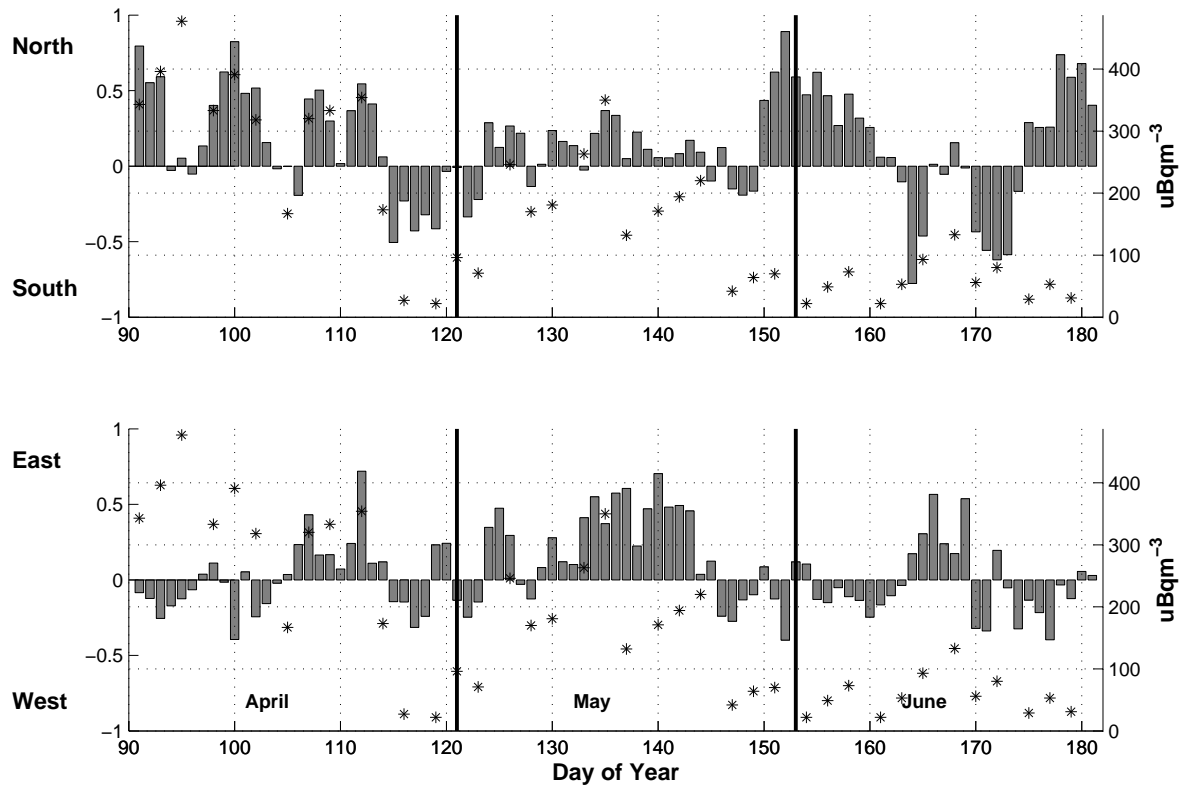

Fig. 9c. Each day vectorized trajectory for 2001. Upper figure shows the N-S together with ${ }^{210} \mathrm{~Pb}$ concentration (stars). Lower figure shows the corresponding E-W contribution for each day trajectory.

lifetime of ${ }^{210} \mathrm{~Pb}$ in the atmosphere is intimately linked to aerosols through being attached to accumulation-mode particles (cf. Fig. 8b). The accumulation-mode particles are typically where the largest surface area can be found and thus the largest sink for condensable species. New particle formation is a non-linear process that involves the competition between the sink of condensable species and the source of the same. Therefore, the alternative scenario can be formu- lated: Can annual systematic changes in the source strength and sink rate of the condensable species together give the type of transition that the aerosol properties show? 


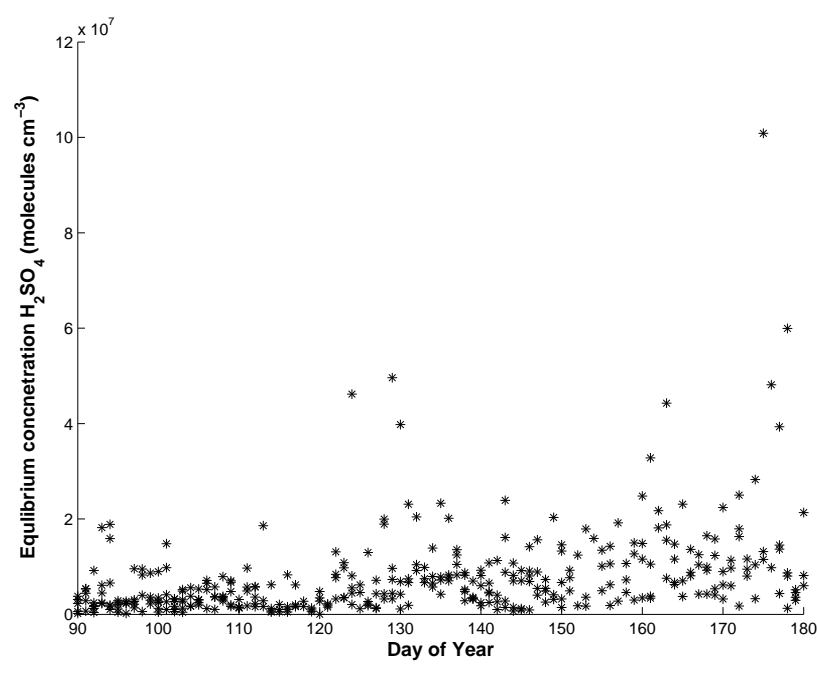

Fig. 10. Equilibrium vapour concentrations $\mathrm{H}_{2} \mathrm{SO}_{4}$ April through June for the years 2000-2005. Based on incoming solar radiation data, $\mathrm{SO}_{2}$ and aerosol measurements from $\mathrm{Ny}$-Ålesund, Svalbard.

\subsection{Nucleation potential}

\subsubsection{Method}

To explore the possible link between the observed springsummer transition in aerosol size distribution with respect to aerosol nucleation potential we first assume that the newparticle formation involves sulphuric acid $\left(\mathrm{H}_{2} \mathrm{SO}_{4}\right)$. The equilibrium vapour concentration of $\mathrm{H}_{2} \mathrm{SO}_{4}$ is calculated for each day based on daily average data, for which the source rate and sink rate of $\mathrm{H}_{2} \mathrm{SO}_{4}$ is balanced. Following Kulmala et al. (2005) the time dependent vapour concentration of $\mathrm{H}_{2} \mathrm{SO}_{4}, \mathrm{C}$, can be written as

$\frac{d C}{d t}=Q-\mathrm{CS} \cdot \mathrm{C}$,

Where $Q$ is the source rate and CS is the condensational sink. Equilibrium vapour concentration here refers to zero rate of change and is equal to $d C / d t=0$ and thus a balance of the source and sink. The equilibrium vapour concentration of $\mathrm{H}_{2} \mathrm{SO}_{4}, \mathrm{C}$, is then given by

$\mathrm{C}=\frac{Q}{\mathrm{CS}}$

\subsubsection{Source}

The source rate $Q$, is calculated by

$k \cdot \mathrm{OH} \cdot \mathrm{SO}_{2}$,

Where $k$ is the reaction rate $10^{-12}\left(\mathrm{~s}^{-1}\right)$ (Seinfeld and Pandis, 1998) and $\mathrm{SO}_{2}$ are observed daily averages expressed as molecules per $\mathrm{cm}^{-3}$. The $\mathrm{OH}$ radical is not observed and was parameterized from the global radiation observations $S\left(\mathrm{Wm}^{-2}\right)$ http://www.awibremerhaven.de/MET/
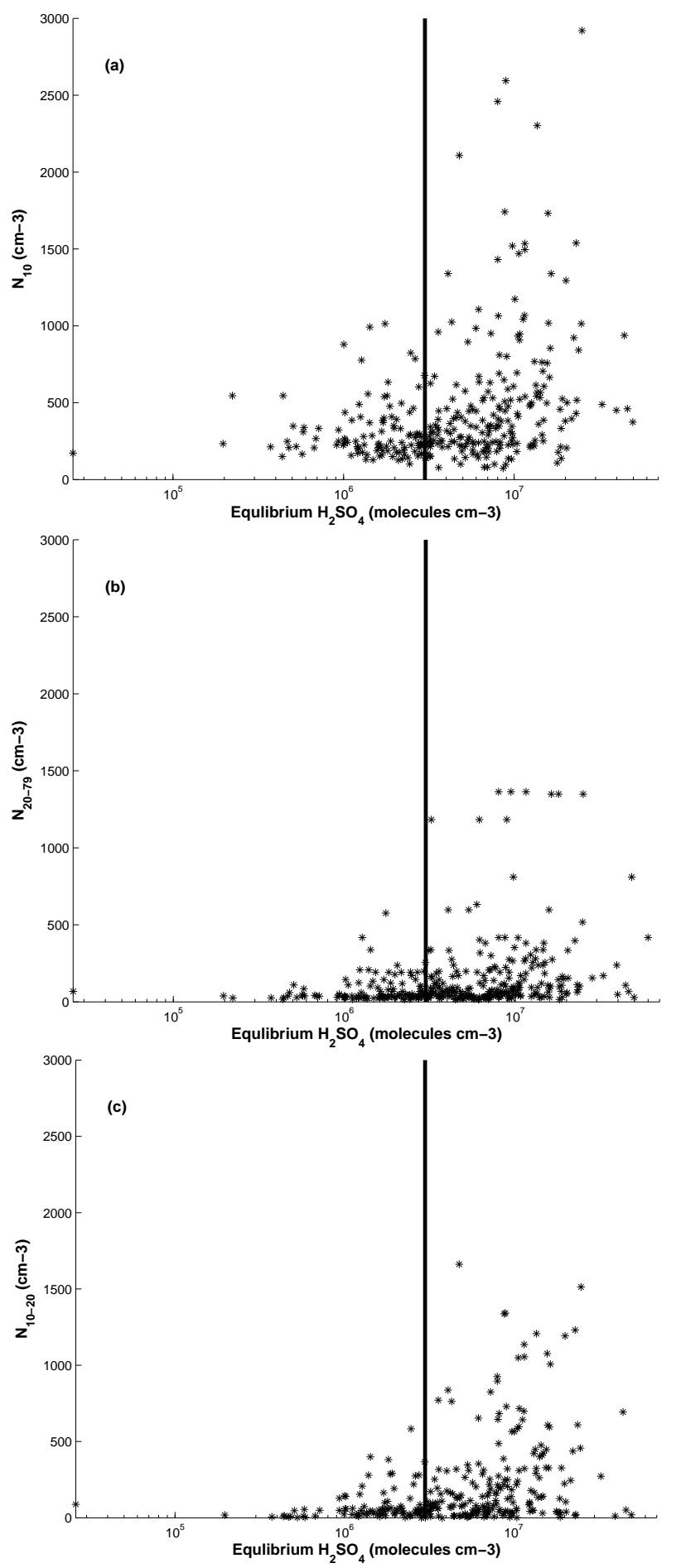

Fig. 11. Number densities for three different ranges of particles sizes; (a) Total number densities $\mathrm{N}_{10}$ based on measurements from CPC, (b) Aitken based on measurements from the DMPS system and (c) smaller sizes $10-20 \mathrm{~nm}$ using the $\mathrm{N}_{10}$ minus integral total number from the DMPS, plotted as a function of the calculated equilibrium vapour concentration of $\mathrm{H}_{2} \mathrm{SO}_{4}$ April through June 2000 2005 . 
NyAlesund/fulltimeresquery.html). To calculate $\mathrm{OH}$ concentration, $S$ was simply scaled by a maximum value (387) of the total data set for observed diffuse solar radiation and multiplied by $5 \times 10^{6}$ according to Eq. (4).

$$
\frac{S \cdot 5 \times 10^{6}}{387} \text {. }
$$

As actual ${ }^{\bullet} \mathrm{OH}$ concentrations are unknown to us, this scaling is entirely arbitrary and only serves to reproduce typical values for ${ }^{\bullet} \mathrm{OH}$ concentrations frequently reported in the literature (Seinfeld and Pandis, 1998).

\subsubsection{Sink}

The condensational sink is calculated based on observed size distributions following Kulmala et al. (2001), including the correction factor for the transition between the molecular and continuum regimes given by:

$$
\mathrm{CS}=2 \pi D \int_{0}^{\infty} d_{p} \beta_{M}\left(d_{p}\right) n\left(d_{p}\right) d d_{p}=2 \pi D \sum_{i} \beta_{M} d_{p, i} N_{i}
$$

Where $D$ is the diffusion coefficient, $n(d p)$ is the particle size distribution function and $N_{i}$ is the concentration of particles in the size section $i$. For the transitional correction factor for the mass flux $\beta_{M}$ we use the Fuchs-Sutugin expression (Fuchs and Sutugin, 1971).

To derive the condensational sink, $\mathrm{CS}\left(\mathrm{s}^{-1}\right)$, the hourly averaged size-distributions for particles larger than $90 \mathrm{~nm}$ (accumulation-mode particles) were used. The reason for restricting the condensational sink only to the accumulationmode particles is that Aitken particles are a result of relatively recent particle production, whereas the accumulationmode particles were most likely already present and available as a sink at the time the new particles were formed. CS was calculated from the hourly average of particle data. We exclude days with less than 10 data points (hourly averages). It should also be noted that CS is calculated based on dry aerosol due to the measurement set-up (cf. Sect. 2.2).

Typically, the Arctic summer boundary layer is often very humid. We have evaluated the relative humidity $(\mathrm{RH})$ data from the Zeppelin station to investigate the hygroscopic effect on aerosols and CS. The influence of RH will affect the calculated condensation sink that is used to estimate the equilibrium concentration of sulphuric acid. The relevant issue here is if including RH makes CS change with time differently than by not including RH.

RH data are available only for years 2002 to 2005 and hence not for the entire data set. We consider hygroscopic growth for an $\mathrm{H}_{2} \mathrm{SO}_{4}$-aerosol, following the approximation by Köpke et al. (1997). The result shows that the hygroscopic growth affects the aerosol with almost the same magnitude over the entire period. Comparing CS for these two conditions, with or without including hygroscopic growth, show a CS increase with a factor 1.8 in April, 1.7 in May and a factor of 2 in June. Hence the equilibrium concentration of $\mathrm{H}_{2} \mathrm{SO}_{4}$ vapour will decrease about a factor of two over the entire 3-month period, but the difference between the months are not large enough to explain the transition observed in equilibrium concentration of $\mathrm{H}_{2} \mathrm{SO}_{4}$. If anything, the slightly higher CS in summer compared to spring would tend to make the transition less pronounced. We therefore use the dry aerosol size, which makes it possible for us to use a larger data set.

\subsubsection{Result}

Following the above formulas the equilibrium $\mathrm{H}_{2} \mathrm{SO}_{4}$ concentration was calculated based on the average incoming radiation, $\mathrm{SO}_{2}$ and $\mathrm{CS}$ for each day. In Fig. 10 these values for the data set is plotted as function of day. The data ranges from close to zero to around $1 \times 10^{8}$ molecules $\mathrm{cm}^{-3}$ with an increasing trend with time, even though the main part of data falls between $8 \times 10^{5}$ and $3 \times 10^{7}$ molecules $\mathrm{cm}^{-3}$. We were interested to find out whether there is any particular value of $\mathrm{C}$ above where small particles are more likely to occur. To do this we analysed the observed integral aerosol number densities of various sizes versus C Fig. 11a-c. There are different amounts of data in each scatter plot presented in Fig. 11a-c due to reduction of the time resolution for individual instruments. Note that data in Fig. 11a and b are entirely independent, whereas in Fig. 11c the accumulation mode part of the size distribution enters both variables.

All three scatter plots present a systematic trend with more frequent high number densities as $\mathrm{C}$ increases. However, it is difficult to distinguish a very clear critical value for $\mathrm{C}$ that would indicate a nucleation threshold. Based on the three scatter plots it appears that a value of $\mathrm{C}$ above approximately $3 \times 10^{6}$ molecules $\mathrm{cm}^{-3}$ separates $\mathrm{C}$ values with generally low number densities and $C$ values associated with the highest number densities.

Note that we work with daily averages given by measured data from Ny-Ålesund. Newly formed particles may take several hours, up to a day, to reach a size of $10 \mathrm{~nm}$ (detectable size for the instrument) due to the low concentration of condensable material in the Arctic. Hence, the observed conditions when there are high number-densities of aerosols in $\mathrm{Ny}-$ Ålesund are not necessarily identical to the conditions existing where the particle formation actually took place. To give the reader a feeling for the spatial scale of our approach we might think of how far an air parcel is transported in one day. Given a mean wind speed of $5 \mathrm{~ms}^{-1}$ this distance is equivalent to more than $400 \mathrm{~km}$ transport during one day. This means that processes taking place $400 \mathrm{~km}$ from $\mathrm{Ny}$-Ålesund affect our daily averages.

The present study is not aimed at a detailed analysis of the nucleation process, but rather to characterize the conditions related to the observed changes in aerosol characteristics. By necessity the analysis of the data becomes schematic in many aspects, as there are many processes that interplay. 

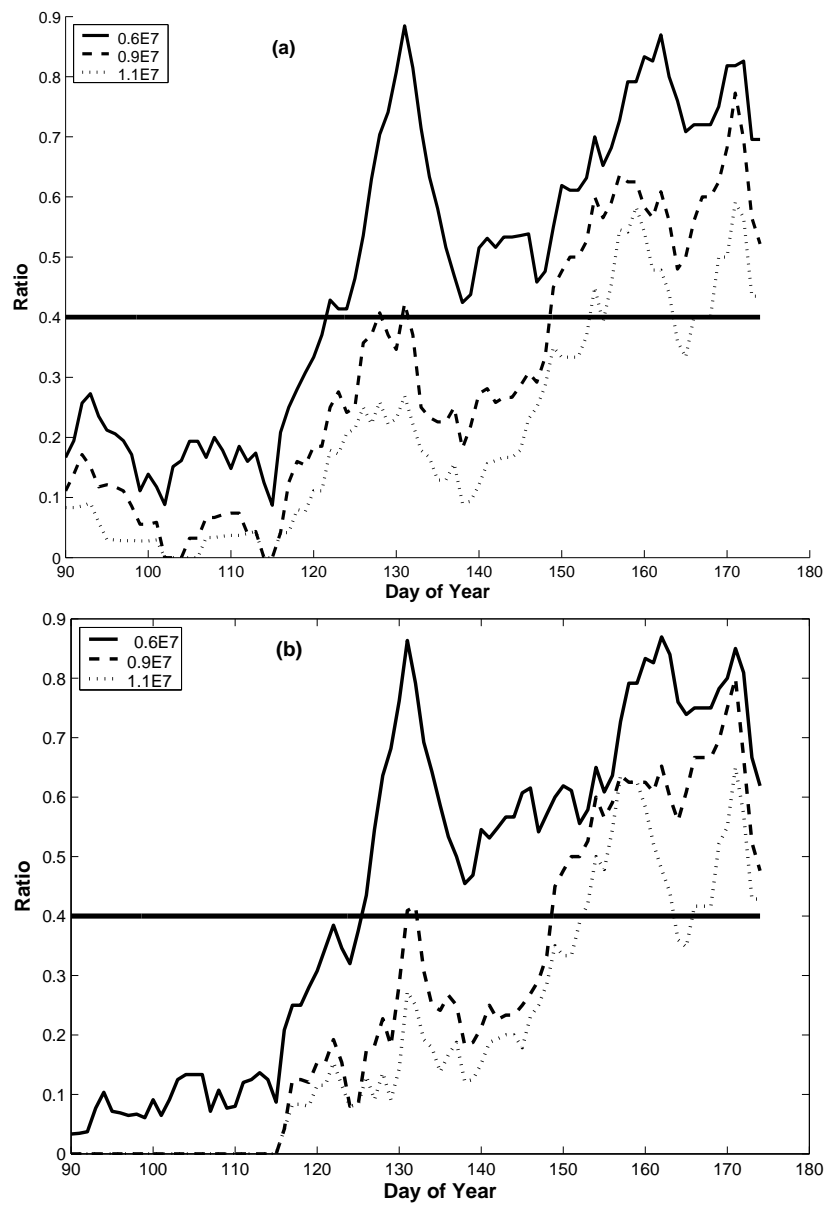

Fig. 12. (a) Fraction for when a certain criteria, $0.6 \times 10^{7}$ molecules cm $\mathrm{cm}^{-3}$ (solid) $\quad 0.9 \times 10^{7}{\text { molecules } \mathrm{cm}^{-3}}^{-3}$ (dashed) and $1.1 \times 10^{7}$ molecules $\mathrm{cm}^{-3}$ (dotted) of the equilibrium vapour concentrations of $\mathrm{H}_{2} \mathrm{SO}_{4}$ occur. (b) Same as (a) but excluded for polluted events.

We are interested in singling out the most important factors and therefore we omit details in favour of trends. The results here will therefore only illustrate the trend in data found in the Arctic region and will not describe the nucleation processes in detail.

\subsubsection{Trace gases influence on observed aerosol loading}

Whether or not the critical value is below or above $3 \times 10^{6}$ molecules $\mathrm{cm}^{-3}$ we can see the potential effect of such a threshold on the size distribution over time. We may think of it as a nucleation potential. Moreover, it is not only of interest if the conditions meet the threshold, but also to what extent $\mathrm{C}$ may exceed above this values, as seen from Fig. 11a. We illustrate this by making a weekly moving average of the ratio between the number of data points exceeding a certain threshold, divided by the total number of data points for the time window over all six years. If the equilib- rium threshold is reached often we expect that formation of particles occur readily during that time. The higher the value of this threshold, the more vigorous we expect the particle formation to be.

We explore three different values of the $\mathrm{H}_{2} \mathrm{SO}_{4}$ equilibrium concentration threshold: $0.6 \times 10^{7} ; 0.9 \times 10^{7}$; and $1.1 \times 10^{7}$ molecules $\mathrm{cm}^{-3}$ (see Fig. 12a). From comparing the different ratios it is clear that changing the threshold from $0.6 \times 10^{7}$ to $1.1 \times 10^{7}$ molecules $\mathrm{cm}^{-3}$ has the largest impact on the evolution of the ratios in the middle of the time period, where the reduction in the ratio is twice as large as at both ends of the time period. Thus, the difference between the ratios in April and May compared with June are accentuated. This is most evident for the highest threshold value; there the ratio increases from low values to about 0.2 over the first two months and then quickly increases to above 0.4 in about a week's time.

A small amount of data (about 6\%) is clearly affected by rapid transport from anthropogenic sources evident in the very high $\mathrm{SO}_{2}$ concentrations for the time period. These high $\mathrm{SO}_{2}$ concentrations would yield enhanced values of equilibrium $\mathrm{H}_{2} \mathrm{SO}_{4}$. As we only consider the aerosol size distribution up to $630 \mathrm{~nm}$ (due to the limitation of the measuring equipment) in calculating $\mathrm{CS}$, it is possible that a significant contribution to CS from larger particles is missed during strong pollution events. This would result in an underestimation of $\mathrm{C}$, whereas nucleation events are typically quenched in polluted air due to large aerosol surface area. To test the influence of these events on our results we repeated the ratio calculation after screening data where $\mathrm{SO}_{2}$ exceed $0.6 \times 10^{7}$ molecules per $\mathrm{cm}^{-3}$ (see Fig. 12b). This limit was chosen by investigating data for when $\mathrm{SO}_{2}$ concentration reached high values that were probably influenced by anthropogenic sources. Excluding the pollution events generates no large changes between Fig. 12a and b. But excluding these outliers makes the transition from low ratios in the beginning of the period to higher ratios in June somewhat clearer. The highest threshold for instance never occurs before day 115 . Between day 115 and day 145 the fraction of time the threshold is exceeded increase to $20 \%$. Only 10 days later this fraction is more than doubled and from about day 155 the fraction hovers around 50\%. Hence in late May and beginning of June the occurrence of the potential conditions for particle formation increases dramatically.

\section{Discussion}

Transport patterns and source strengths of anthropogenic tracers change over the year with the net effect that the Arctic atmosphere in the late winter and spring period is the most polluted and that summer is the cleanest period of the year. Over the time period from spring to summer, the aerosol characteristics change from being dominated by the accumulation-mode to being primarily of the Aitken-mode 
variety. Our observations and analysis show that this transition is not typically a gradual change but occur over a rather short period in late May/early June each year, and takes around 10 days. Intrigued by the temporal persistence of the transition we systematically investigated pertinent tracers and transport patterns over the period April-June during a six-year period (2000-2005).

If the transition from spring- to summer-aerosol could be explained by transport alone, we would expect that the main transport pattern should change from one regime to another i.e. a change from anthropogenic sources at lower latitudes to biogenic sources from the north, which in present study is not the case. Although seasonal changes in the flow pattern exist (Eneroth et al., 2003; Stohl, 2006) our analysis could not reveal any systematic pattern that could help explain the rapid transition observed for the aerosol properties.

The levels of DMS may be largest in the latter part of the summer (Ferek et al., 1995), but the overall concentrations of $\mathrm{SO}_{2}$ decrease over the investigated time period. Therefore there may be a debate about what process actually formed the $\mathrm{SO}_{2}$ molecule; anthropogenic versus natural, and a biogenic source, via its sulphur cycle, cannot explain the transition. The fact that the $\mathrm{SO}_{2}$ values are at their lowest during the period with most active particle production is perhaps unexpected. Shaw (1989) discussed particle formation in clean areas and suggested that one viable pathway is the cleaning of pre-existing aerosol area through precipitating clouds.

The temporal evolution of the condensational sink, CS, depicted as a weekly running mean in Fig. 13a indeed shows persistently low values from about day 150 and onwards. The temporal characteristics of CS in many ways resemble those presented by ${ }^{210} \mathrm{~Pb}$ in Fig. 8a. As a matter of fact, the correlation between these two variables is better than 0.92 . As the ${ }^{210} \mathrm{~Pb}$ is associated with accumulation-mode particles this close relation can be understood. We note that whereas ${ }^{210} \mathrm{~Pb}$ continues to decrease during the period of investigation, CS appears to recover at the end. $\mathrm{As}{ }^{210} \mathrm{~Pb}$ is a tracer for continental air masses, this deviation between the two variables would be consistent with a rebuilding of the aerosol surface area that takes place within the Arctic basin or over ocean further south. Given the typically low wind speeds in the Arctic summer atmosphere (Heintzenberg et al., 1991; Eneroth et al., 2003; Stohl, 2006), the decrease in ${ }^{210} \mathrm{~Pb}$ and increase in CS are most likely a result of secondary aerosol formation taking place within the Arctic.

At the same time as clouds remove pre-existing aerosol surface area and pave the way for new particle nucleation, clouds also scavenge $\mathrm{SO}_{2}$ through liquid oxidation and produce particulate sulphate on already existing particles. This removal of $\mathrm{SO}_{2}$ will in turn reduce the potential for subsequent nucleation of new particles. The fact that the monthly mean $\mathrm{SO}_{2}$ concentration is about half in June of what it is in April and May (cf. Table 2) is consistent with scavenging and reduced anthropogenic sources.
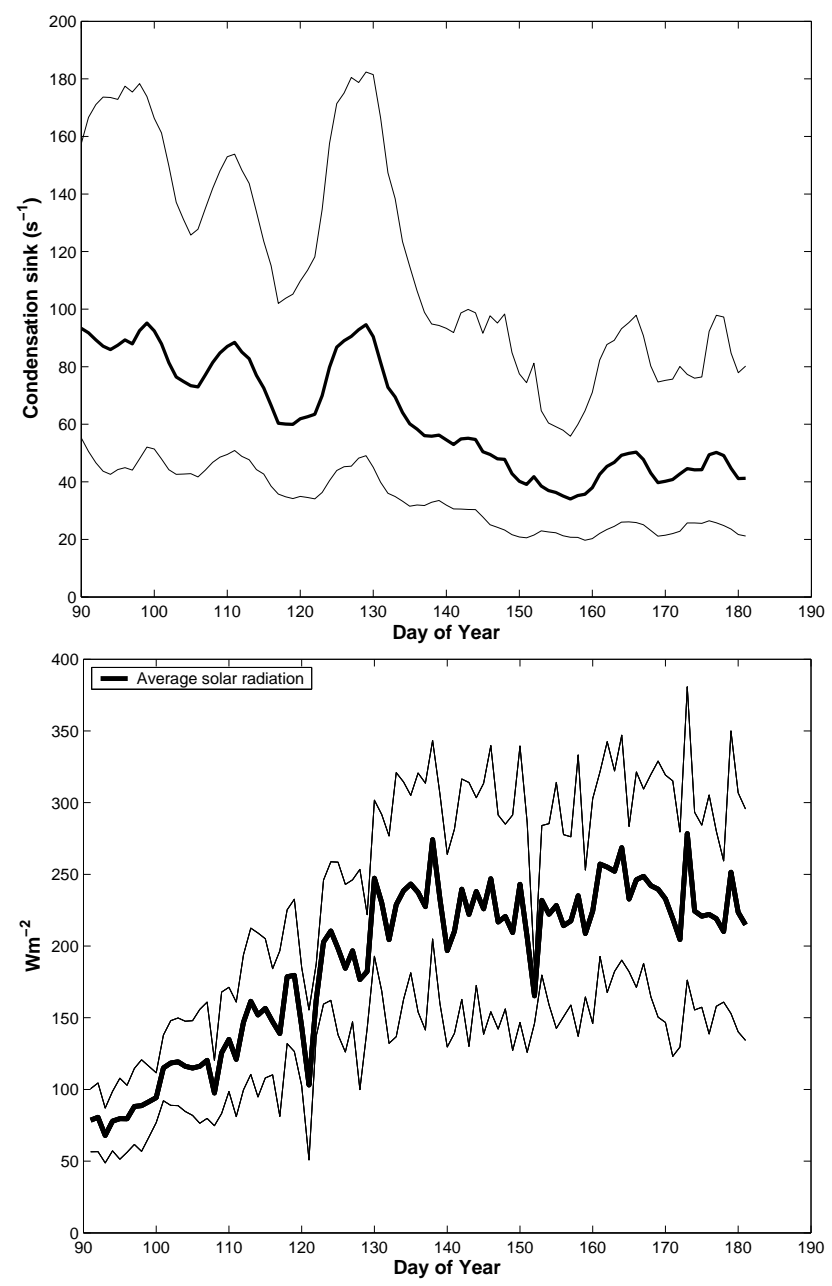

Fig. 13. (a) Running weekly mean and standard deviation of the derived condensations sink (CS) (derived from Eq. (5)), based on DMPS data from the Zeppelin station for the years 2000-2005. (b) Average solar radiation at Ny-Ålesund for the years 2000-2005.

A complicating aspect with respect to the discussion above about scavenging of $\mathrm{SO}_{2}$ by clouds is that, if one studies the temporal evolution of $\mathrm{SO}_{2}$ over the last part of June, it appears as if $\mathrm{SO}_{2}$ increases (Fig. 7a). It is not obvious how to fit this behaviour with the observation of ${ }^{210} \mathrm{~Pb}$ and $\mathrm{CS}$ above. On the one hand it may be indicative of an increasing marine source of $\mathrm{SO}_{2}$ associated with the summer-time biological activity in the ocean through oxidation of DMS and subsequent formation to $\mathrm{SO}_{2}$. On the other hand this increase may be a greater influence from anthropogenic sources during parts of the summer as reported by (Heintzenberg, 1989). In the latter case the scavenging of accumulation-mode particles must be efficient while letting some fraction of $\mathrm{SO}_{2}$ survive the cloud passage or passages. Nevertheless, the question about the origin of $\mathrm{SO}_{2}$ in the summer Arctic, anthropogenic versus natural is an interesting one in relation 
to aerosol-cloud interactions and climate forcing, and needs further investigation.

The third leg in this simple method to determine the nucleation potential is solar radiation, which in turn is a proxy for $\mathrm{OH}$ in the atmosphere. A close relationship between the yearly cycle of particle number density and incoming solar radiation at Ny-Ålesund, which supports the importance of photochemical reactions has been shown by Ström et al. (2003). At about mid-March the sun returns to the Svalbard region and the summer solstice occur about three weeks into June. Hence, the spring-to-summer period presents a dramatic increase in the amount of radiation that reaches $\mathrm{Ny}$ Ålesund. Therefore, the decrease in the precursor gas $\mathrm{SO}_{2}$ due to changes in transport patterns is more than compensated for by the combined effect of an increased radiation flux and decreased condensational sink.

This is illustrated by using some simple numbers. $\mathrm{SO}_{2}$ decrease by about a factor of 2 between the beginning and end of the time period (cf. Table 2). The condensational sink decreases over the same time by about a factor of 2 (cf. Fig. 13a). However, the weekly median radiation increases by about a factor of 5 (Fig. 13b). Hence, the temporal evolution of $\mathrm{CS}$ and $\mathrm{SO}_{2}$ largely compensate each other and the nucleation potential is mainly driven by the radiation. The net effect is that the nucleation potential reaches some critical value at about the same time each year.

Particle nucleation is highly non-linear and some critical super-saturation of condensable vapour must be reached before new particles will form. Below this value nucleation does not readily occur. For instance, the more this critical value is exceeded, the larger the chance is that the newly formed particles will grow to sizes that can be detected by the instruments at the Zeppelin station. Based on the temporal evolution of the Aitken mode in Fig. 3a and the aerosol transition index in Fig. $4 \mathrm{a}$ and $\mathrm{b}$ we believe that this critical value is typically meet every year around day 145 plus or minus a week. Hence we believe that photochemical reactions govern much of the aerosol dynamics in the Arctic.

The whole picture is further complicated by the fact that remote sensing data shows similar sudden change in aerosol properties, which indicates the whole troposphere to be involved in a similar transition. Remote sensing within the Stratospheric Aerosol and Gas Experiment (SAGE) II and III suggests a change between spring and summer for the optical properties of the Arctic aerosol in the upper free troposphere above $4 \mathrm{~km}$ altitude (Treffeisen et al., 2006). Whether same processes in the BL control this remains to be investigated.

\section{Summary and conclusions}

The main motivation for this study was to investigate the spring - summer period (April, May, and June), with emphasis on the transition in aerosol properties observed in the Arctic troposphere on an annual basis. In the study we have used four-day-back trajectories and long-term observations of aerosols and trace gases from the Zeppelin station, Svalbard. We have described the difference between the periods of spring and summer, the transition between them, and we have attempted to link the observations to the large-scale circulation and influences from natural and anthropogenic sources of aerosols and gases. We have investigated the hypothesis that air-mass transport to the Arctic controls the systematic change in the physical properties of aerosols (i.e. from being dominated by accumulation-mode in spring to being Aitken-mode dominated in summer) that are observed at the Zeppelin station. To summarise this work, we ended up with four main conclusions:

1. Using air mass back-trajectories we have shown that transport alone cannot explain the repeating rapid transition from spring-type to summer-type aerosol observed in the Arctic troposphere.

2. Blocking the advection of the polluted air masses from south into the Arctic is important contributor to transport, but it should be seen more as a necessary prerequisite rather than the main process controlling the springsummer transition in aerosol properties. The reduction of the anthropogenic contribution (using $\mathrm{CO}$ as tracer) during the investigated period presents a rather smooth trend and cannot alone explain the sudden change in aerosol properties.

3. With a simplified model, which delivers the nucleation potential for new-particle formation in the form of equilibrium vapour concentration of $\mathrm{H}_{2} \mathrm{SO}_{4}$, we suggest that the aerosol microphysical properties are the result of a delicate balance between incoming solar radiation, transport, and condensational sink processes.

4. The temporal evolution of the condensational sink and $\mathrm{SO}_{2}$ concentrations indicate that, to a large degree, they compensate each other and the nucleation potential is mainly driven by solar radiation. The strong seasonality of the solar angle in the Arctic results in the nucleation potential reaching some critical value about the same time each year. This is consistent with a repeating pattern of aerosol transition between spring and summer.

At this time, it is not clear how and to what extent processes in the boundary layer and the free troposphere are interlinked. In order to get better insight into this phenomenon, airborne in-situ measurements covering the whole tropospheric column are necessary.

Acknowledgements. The authors wish to acknowledge C. Lunder (NILU), B. Noone (ITM) and J. Waher (ITM) for providing us with data from the Zeppelin station. The monitoring at the Zeppelin station is supported by the Swedish Environmental Protection Agency and by the Swedish National Science Foundation. Support has also been received from the Swedish Polar Secretariat. The FMI's ${ }^{210} \mathrm{~Pb}$ 
measurements at Mt. Zeppelin are made in collaboration with the Norwegian Institute for Air Research (NILU) and the Norwegian Polar Institute (NPI).

Edited by: K. Carslaw

\section{References}

Beine, H. J.: Measurements of CO in the high Arctic, Glob. Change Sci. 1, 145-151, 1999.

Barrie, L. A.: Arctic Air-Pollution - an Overview of Current Knowledge, Atmos. Environ., 20, 643-663, 1986.

Bodhaine, B. A., Harris, J. M., and Herbert, G. A.: Aerosol LightScattering and Condensation Nuclei Measurements at Barrow, Alaska, Atmos. Environ., 15, 1375-1389, 1981.

Bodhaine, B. A.: Barrow Surface Aerosol - 1976-1986, Atmos. Environ., 23, 2357-2369, 1989.

Dianovklokov, V. I. and Yurganov, L. N.: Spectroscopic Measurements of Atmospheric Carbon-Monoxide and Methane. 2. Seasonal-Variations and Long-Term Trends, J. Atmos. Chem., 8, 153-164, 1989.

Eneroth, K., Kjellström, E., and Holmén, K.: A trajectory climatology for Svalbard; investigating how atmospheric flow patterns influence observed tracer concentrations, Phys. Chem. Earth, 28, 1191-1203, 2003.

Ferek, R. J., Hobbs, P. V., Radke, L. F., Herring, J. A., Sturges, W. T., and Cota, G. F.: Dimethyl sulfide in the arctic atmosphere, J. Geophys. Res.-Atmos., 100, 26 093-26 104, 1995.

Fuchs, N. A. and Sutugin, A. G.: Highly dispersed aerosols, Ann. Arbor. Sci. Publ., Michigan, 1970.

Garrett, T. J., Hobbs, P. V., and Radke, L. F.: High Aitken nucleus concentrations above cloud tops in the Arctic, J. Atmos. Sci., 59, 779-783, 2002

Garrett, T. J., Zhao, C., Dong, X., Mace , G. G., and Hobbs, P. V.: Effects of varying aerosol regimes on low-level Arctic stratus, Geophys. Res. Lett., 31, L17105, doi:10.1029/2004GL019928, 2004.

Hassol, S. J.: ACIA, Impacts of a Warming Arctic, Arctic Climate Impact Assessment, Cambridge University Press, 2005.

Heintzenberg, J.: Arctic Haze - Air-Pollution in Polar-Regions, Ambio, 18, 50-55, 1989.

Heintzenberg, J. and Larsson, S.: $\mathrm{SO}_{2}$ and $\mathrm{SO}_{4}$ in the Arctic: interpretation of observations at three Norwegian arctic sub arctic stations, Tellus, 35B, 255-265, 1983.

Heintzenberg, J., Ström, J., Ogren, J. A., and Fimpel, H. P.: Vertical Profiles of Aerosol Properties in the Summer Troposphere of Central-Europe, Scandinavia and the Svalbard Region, Atmos. Environ., 25, 621-627, 1991.

Jokinen, V. and Makela, J. M.: Closed-loop arrangement with critical orifice for DMA sheath excess flow system, J. Aerosol Sci., 28, 643-648, 1997.

Knutson, E. O. and Whitby, K. T.: Aerosol classification by electric mobility: apparatus, theory and applications, J. Aerosol Sci., 6, 443-451, 1975.

Köpke, P., Hess, H., Schult, I., and Shettle, E.: The Global Aerosol Data Set (GADS), MPI-Rep., Hamburg, 243, 44 pp., 1997.

Kulmala, M., Dal Maso, M., Makela, J. M., Pirjola, L., Vakeva, M., Aalto, P., Miikkulainen, P., Hameri, K., and O'Dowd, C. D.:
On the formation, growth and composition of nucleation mode particles, Tellus B, 53, 479-490, 2001.

Kulmala, M., Petaja, T., Monkkonen, P., Koponen, I. K., Dal Maso, M., Aalto, P. P., Lehtinen, K. E. J., and Kerminen, V. M.: On the growth of nucleation mode particles: source rates of condensable vapour in polluted and clean environments, Atmos. Chem. Phys., 5, 409-416, 2005, http://www.atmos-chem-phys.net/5/409/2005/.

Li, S. M. and Barrie, L. A.: Biogenic Sulfur Aerosol in the Arctic Troposphere. 1. Contributions to Total Sulfate, J. Geophys. Res.Atmos., 98, 20 613-20 622, 1993.

Li, S. M., Barrie, L. A., and Sirois, A.: Biogenic Sulfur Aerosol in the Arctic Troposphere .2. Trends and Seasonal-Variations, J. Geophys. Res.-Atmos., 98, 20 623-20 631, 1993.

Mattsson, R., Paatero, J., and Hatakka, J.: Automatic alpha beta analyser for air filter samples - Absolute determination of radon progeny by pseudo-coincidence techniques, Radiat. Prot. Dosim., 63, 133-139, 1996.

Mitchell, J. M.: Visual range in the Polar Regions with particular references to the Alaskan Arctic, J. Atmos. Terr. Phys. Spec. Suppl., 195-211, 1957.

Nilsson, E. D.: Planetary boundary layer structure and air mass transport during the International Arctic Ocean Expedition 1991, Tellus B, 48, 178-196, 1996.

Paatero, J. and Hatakka, J.: Source areas of airborne Be-7 and $\mathrm{Pb}$ 210 measured in Northern Finland, Health Phys., 79, 691-696, 2000.

Paatero, J., Hatakka, J., Holmen, K., Eneroth, K., and Viisanen, Y. Lead-210 concentration in the air at Mt. Zeppelin, Ny-Ålesund, Svalbard, Phys. Chem. Earth, 28, 1175-1180, 2003.

Quinn, P. K., Miller, T. L., Bates, T. S., Ogren, J. A., Andrews, E., and Shaw, G. E.: A 3-year record of simultaneously measured aerosol chemical and optical properties at Barrow, Alaska, J. Geophys. Res.-Atmos., 107(D11), 4130, doi:10.1029/2001JD001248, 2002.

Rahn, K. A.: The Mn-V Ratio as a Tracer of Large-Scale Sources of Pollution Aerosol for the Arctic, Atmos. Environ., 15, 14571464, 1981.

Seinfeld, J. H. and Pandis, S. P.: Atmospheric Chemistry and Physics, A Wiley-Interscience Publication, Canada, p. 250, 1998.

Shaw, G. E.: Production of Condensation Nuclei in Clean-Air by Nucleation of H2so4, Atmos. Environ., 23, 2841-2846, 1989.

Shiobara, M., Yabuki, M., and Kobayashi, H.: A polar cloud analysis based on Micro-pulse Lidar measurements at Ny-Ålesund, Svalbard and Syowa, Antarctica, Phys. Chem. Earth, 28, 12051212, 2003.

Stohl, A., Haimberger, L., Scheele, M. P., and Wernli, H.: An intercomparison of results from three trajectory models, Meteorol. Appl., 8, 127-135, 2001.

Stohl, A.: Characteristics of atmospheric transport into the Arctic troposphere, J. Geophys. Res.-Atmos., 111, D11306, doi:10.1029/2005JD006888, 2006.

Ström, J., Umegård, J., Torseth, K., Tunved, P., Hansson, H. C., Holmén, K., Wismann, V., Herber, A., and Konig-Langlo, G.: One year of particle size distribution and aerosol chemical composition measurements at the Zeppelin Station, Svalbard, March 2000-March 2001, Phys. Chem. Earth, 28, 1181-1190, 2003.

Tjernström, M.: The summer arctic boundary layer during the Arctic Ocean Experiment 2001 (AOE-2001), Bound.-Lay. Meteo- 
rol., 117, 5-36, 2005.

Treffeisen, R. E., Thomason, L. W., Strom, J., Herber, A. B., Burton, S. P., and Yamanouchi, T.: Stratospheric Aerosol and Gas Experiment (SAGE) II and III aerosol extinction measurements in the Arctic middle and upper troposphere, J. Geophys. Res.Atmos., 111, D17203, doi:10.1029/2005JD006271, 2006.

Wiedensohler, A.: An Approximation of the Bipolar ChargeDistribution for Particles in the Sub-Micron Size Range, J. Aerosol Sci., 19, 387-389, 1988.
Williams, J., de Reus, M., Krejci, R., Fischer, H., and Strom, J.: Application of the variability-size relationship to atmospheric aerosol studies: estimating aerosol lifetimes and ages, Atmos. Chem. Phys., 2, 133-145, 2002, http://www.atmos-chem-phys.net/2/133/2002/.

Virkkula, A., Makinen, M., Hillamo, R., and Stohl, A.: Atmospheric aerosol in the Finnish Arctic: Particle number concentrations, chemical characteristics, and source analysis, Water Air Soil Poll., 85, 1997-2002, 1995. 